\title{
The innovation effects of renewable energy policies and their interaction: the case of solar photovoltaics
}

\author{
Kristoffer Palage $^{1} \cdot$ Robert Lundmark $^{1} \cdot$ Patrik Söderholm $^{1}$
}

Received: 20 October 2017 / Accepted: 6 October 2018 / Published online: 17 October 2018

(c) The Author(s) 2018

\begin{abstract}
The objective of this paper is to examine the innovation impacts of renewable energy support policies, and their interaction in the empirical context of solar photovoltaics (PV) technology. This is achieved using data on patent applications for 13 countries over the period 1978-2008, and unconditional negative binomial estimators. The analysis addresses one technology-push instrument, public R\&D support, and two demand-pull instruments, feed-in tariffs (FIT), and renewable energy certificate (REC) schemes. The results indicate that: (a) both FIT and REC schemes induce solar PV patenting activity, but the impact of the former policy appears to be more profound; (b) public R\&D support has overall been more influential than FIT and REC schemes in encouraging solar PV innovation; (c) policy interaction exists in that the impact of public R\&D support on innovation is greater at the margin if it is accompanied by the use of FIT schemes for solar PV. A corresponding interaction effect is harder to detect for public R\&D support and REC schemes, possibly due to the stronger technology selection pressure under the latter policy. The results following several robustness tests support the existence of a positive interaction effect between public R\&D and FIT schemes.
\end{abstract}

Keywords Innovation - Patent counts $\cdot$ Solar photovoltaics $\cdot$ Renewable energy policy $\cdot$ Policy interaction

JEL Classification $\mathrm{O} 34 \cdot \mathrm{O} 38 \cdot \mathrm{Q} 55 \cdot \mathrm{Q} 58$

Patrik Söderholm

patrik.soderholm@1tu.se

1 Economics Unit, Luleå University of Technology, 97187 Luleå, Sweden 


\section{Introduction}

\subsection{Background and contribution}

Given the need to limit the increase in global average temperatures to avoid dangerous levels of anthropogenic climate change, the development of low-carbon energy technology such as solar energy and wind power has been a policy priority in many countries. In liberalized energy markets, the circumstances can ,however, often be unfavorable for renewable energy sources - until, recently, these technologies have typically had higher generation costs than the incumbent technologies, and especially if the price of carbon dioxide emissions is low. Moreover, there is also path dependence in the direction of technological and institutional change, which locks the economy into the use of older fossil fuel-based energy technology (Arthur 1989; Unruh 2000; Acemoglu et al. 2012). For these reasons, there is a need to better understand the process of technological innovation in the renewable energy field, and the ways through which various types of public policies can promote this process.

The empirical research linking energy and environmental policy and innovation constitutes a growing literature stream, and overall, the results from such studies indicate a positive effect of public policy on innovation (e.g., Brunnermeier and Cohen 2003; Lanjouw and Mody 1996; Noailly and Batrakova 2010; Popp 2002). The previous research specifically addressing policy-induced innovation in the renewable energy sector is scarcer, and some of it is based mainly on qualitative or theoretical analysis (e.g., Menanteau et al. 2003; Foxon et al. 2005; Sagar and Zwaan 2006; Fischer and Newell 2008). A number of recent empirical studies use quantitative data to investigate technological change in the energy sector and the role of energy prices and policy. For instance, Lanzi and Sue Wing (2011) find a positive relationship between energy prices and innovation in the renewable energy sector. This result was confirmed in Verdolini and Galeotti (2011), which address the innovation impacts of energy prices on different types of energy technologies while also accounting for international knowledge spillovers.

Other important quantitative studies addressing renewable energy innovation include Walz et al. (2008), Karmarkar-Deshmukh and Pray (2009), Johnstone et al. (2010), Rübbelke and Weiss (2011), Noailly and Smeets (2012), Peters et al. (2012), Nesta et al. (2014), Emodi et al. (2015), and Costantini et al. (2015). Most such research employs patent counts as proxy for innovation, and the recent work has also introduced novel methodological approaches. ${ }^{1}$ Many of the available studies, however, use aggregate data for the renewable energy technology sector, and, therefore, tend to downplay the heterogeneity of various technologies. Some of these technologies are technically and commercially relatively mature (e.g., hydropower), while others, such as ocean energy, are less developed, but they may, nevertheless,

\footnotetext{
1 A prominent example is the use of production frontier analysis to estimate efficiency scores, also taking into account technological innovation based on patent stocks. Johnstone et al. (2017) develop this approach, and test it in the empirical context of thermal power plants.
} 
show great potential. This, thus, suggests the existence of differential policy impacts across various types of technologies (see also Nicolli and Vona 2014; Lee and Lee 2013; Fujii and Managi 2016; Schmidt and Sewerin 2018).

In this paper, we address the relationship between public policy support to renewable energy and innovation in the empirical context of solar photovoltaics (PV). We consider the public policies targeting solar PV in 13 different countries since the late 1970s. These policies include technology-push policies in the form of public R\&D support to solar PV as well as two different types of demand-pull policies: feed-in tariffs (FIT) and renewable energy certificates (REC). A FIT scheme is a price-based support in which the producers of renewable electricity sell at a preset (guaranteed) price per kWh generated over a given time-period (e.g., Couture and Gagnon 2010). A REC scheme involves an obligation for retailers to purchase a predetermined amount (in MWh) of renewable electricity. Each MWh of renewable electricity produced in power plants eligible for certificates yields one certificate that can be sold. In this way, a market for the certificates is established where the price of these equals the premium revenue (per MWh) that renewable electricity producers must receive to fulfill the obligation.

By focusing on the above policies, we acknowledge that solar PV innovation may be induced both through basic knowledge generation that private companies can make use of, as well as by the various learning processes on the production side (learning-by-doing, learning-by-using, etc.). FIT and REC schemes both support the generation of solar PV, and thereby also learning.

Still, the innovation impacts of these two deployment policies will also vary due to differences in design. A particularly important design issue is whether the policy is technology-specific or technology-neutral, i.e., whether or not it specifies which technologies (or applications) should be supported. The previous research has argued that technology-neutral deployment policies can lead to an early lock-out of promising technologies (Azar and Sandén 2011; Schmidt et al. 2016; Lehmann and Söderholm 2018) (see also Sect. 2.1). In this context, it is important to note that FIT levels have typically been differentiated with respect to the technology supported, while the existing REC schemes have very seldom involved separate targets for different types of renewable energy technologies (IEA 2004, 2012a, b).

In the frequently cited work by Johnstone et al. (2010), the differential relationships between renewable energy policies and patenting activity are analyzed in a cross-country setting. For instance, the study supports the notion that FIT and REC schemes could have different impacts on innovation. The results indicate that only the FIT schemes induce innovation in solar energy technology, while the REC schemes instead appear to favor innovation in the more mature technologies such as wind power. In another highly relevant paper, Peters et al. (2012) also investigate the differential effects of policy on solar PV patents, however, in their case focusing on the distinction between domestic and foreign technology-push and demand-pull policies. Their results suggest that public R\&D support primarily has had a domestic effect, while both domestic and foreign demand-pull policies have stimulated solar PV innovation. The present paper draws on this important work, but it also develops the analyses of Johnstone et al. (2010) and Peters et al. (2012) in at least three important respects. 
First, Johnstone et al. (2010) focus on solar energy as an aggregate, thus addressing also solar thermal innovation (e.g., innovations in residential solar thermal systems applied for heating and cooling). At the first glance, our sole focus on solar PV may appear like a marginal research contribution, but it permits us to establish more valid links to the two renewable electricity support schemes (both focusing on electricity generation), as well as to the targeted public R\&D efforts. In fact, our empirical results shed some new light on the differential impacts of FIT and REC schemes, respectively, and not the least their interaction (see further below). Moreover, while Peters et al. (2012) also address solar PV, they only use a rough proxy for measuring the impact of demand-pull policies (i.e., capacity additions). For this reason, their study does not permit an assessment of the differential effects of REC and FIT schemes.

Second, in contrast to both Johnstone et al. (2010) and Peters et al. (2012), we provide a more detailed assessment of the role of public R\&D support by acknowledging different ways of operationalizing this policy variable. Specifically, our analysis considers both the role of direct public R\&D expenditures with lagged impacts, as well as a specification in which the public R\&D expenditures instead add to a knowledge stock (with a depreciation rate and time lag). ${ }^{2}$

Third and finally, a few previous cross-country econometric studies-including Johnstone et al. (2010) and Peters et al. (2012) — devote attention to the potential interaction between public R\&D efforts on the one hand and policy instruments stimulating the diffusion of and thus learning in renewable energy technologies on the other. ${ }^{3}$ One exception includes Lindman and Söderholm (2016) with their limited application to wind power and FIT schemes. ${ }^{4}$ In the present paper, we, therefore, add to this research by testing whether the (marginal) impacts of increases in the public R\&D support to solar PV will differ depending on the presence of either FIT or REC schemes, respectively.

\subsection{Purpose and overall approach}

The purpose of this paper is to investigate the differential impacts of various types of renewable energy support policies on innovation in solar PV technology. In doing this, we address the roles of public R\&D expenditures, FIT schemes, and REC schemes, as well as the interaction between public R\&D support on the one hand and the two renewable energy production support schemes on the other. Technological innovation is measured using the counts of patent applications filed under

\footnotetext{
2 Peters et al. (2012) argue that "there is no substantial lag between R\&D and patent applications", (p. 1302). Still, while this may be valid for private $R \& D$, it is much less likely for public $R \& D$, which typically targets more basic and long-term knowledge development (see also Popp 2015).

3 This is also evident in the literature specifying the so-called two-factor learning curves for different renewable energy technologies (e.g., Klaassen et al. 2005; Ek and Söderholm 2010): in these specifications, public R\&D support and learning-by-doing (measured through cumulative capacity) are treated as independent variables.

${ }^{4}$ Costantini et al. (2017) provides a novel approach to analyzing specific characteristics (e.g., 'balancing') of policy mixes for innovation, in their case with an application to energy-efficient technologies.
} 
the so-called Patent Cooperation Treaty (PCT). These patent data can be disaggregated to specific technological areas, and in the solar PV case, we focus on patents related to novel designs of PV systems, cell and cell materials, modules, and grid connection.

The empirical analysis builds on a detailed panel data set of 13 countries over the time-period 1978-2008. We specify reduced form of negative binomial (NB) regression models in which the dependent variable, solar PV patent application counts, is explained by the stringency of the different renewable energy policies, their interaction, as well as a selection of control variables (see further Sect. 2.2). Based on the estimation results, we calculate elasticities of patenting activity with respect to (marginal) changes in the independent variables, thus permitting us to comment on important differential effects of the respective policies and policy interactions.

Specifically, in the empirical section of the paper, we: (a) re-examine the often made claim that FIT schemes are more innovation-promoting than REC schemes in the renewable energy sector (e.g., del Río and Bleda 2012; Johnstone et al. 2010); (b) investigate whether R\&D support induces more solar PV innovation than demand-pull policies through FIT and REC schemes; (c) test the null hypothesis that a marginal increase in public R\&D expenditures to solar PV will have the same impact on patenting activities regardless of whether FIT or REC schemes are in use. We conduct a number of sensitivity analyses to check the robustness of the results.

\subsection{The case of solar PV}

Solar energy is a promising renewable energy source; the solar energy reaching Earth during a single hour roughly corresponds to the amount of energy used by all human activities during 1 year (e.g., IEA 2010). Our sole focus on solar PV permits the use of clean patent categories, thus avoiding innovations in non-electric solar systems applied for residential heating and cooling and, therefore, facilitating the matching with relevant policies. ${ }^{5}$

During more than a decade, solar PV has been the fastest growing renewable energy sector in terms of installed capacity (Kirkegaard et al. 2010). The global PV market grew by an average rate of 49\% each year during the period 2003-2013, and the global cumulative installed PV capacity reached more than $135 \mathrm{GW}$ in 2013 (IEA 2014a). According to IEA (2014b), the bulk of this capacity was distributed among the following countries (in 2013): Germany (with a 25\% market share), China (14\%), Italy (13\%), Japan (10\%), USA (9\%), Spain (4\%), and France (4\%). During recent years, though, the Chinese solar PV sector has become by far the largest in the world. In 2017, Chinese solar PV capacity amounted to $131 \mathrm{GW}$, now representing over $30 \%$ of the global aggregate at $402 \mathrm{GW}$. Solar PV systems can either be grid-connected or stand-alone (off-grid) systems, and the grid-connected systems have so far dominated the global scene (e.g., REN21 2010).

\footnotetext{
5 Solar thermal technology also includes electric systems, i.e., concentrating solar power (CSP) (Bradford 2006; Timilsina et al. 2011). However, although CSP is also primarily used for electricity generation, the global installed capacity has only been a fraction of that of solar PV (Braun et al. 2011).
} 
The major explanation behind this soar in solar PV penetration has been substantial reductions in the costs of this technology. These cost declines can, in turn, be attributed to a fall in core manufacturing costs such as for material and labor, and not least in capacity-related costs for machinery and equipment (Reichelstein and Sahoo 2018). Substantial innovation over the life cycle of solar PV technology explain these developments, not least in the form of early product innovations followed by a significant process innovation. Huenteler et al. (2016) conclude that the latter focus on the production process suggests a predominant role of the economies of scale in manufacturing, learning-by-doing, and innovations in production equipment.

While the development of large-scale production processes largely has been responsible for the observed cost reductions in solar PV technology, the implementation of domestic demand-pull policy instruments has over the years made the higher production levels possible (Kirkegaard et al. 2010). FIT and REC schemes have thus both been key policy instruments to stimulate solar PV market growth (see also Timilsina et al. 2011; Campoccia et al. 2009; Dusonchet and Telaretti 2010; IEA 2004). It is frequently argued that FIT schemes have played a particularly important role, since these guarantee a specific remuneration for certain time-periods, and since the support levels have been based on technology-specific generation costs (e.g., Mendonça 2007; Fouquet and Johansson 2008; Langniss et al. 2009; Klein et al. 2010; Huenteler et al. 2016). In contrast, in most REC schemes, the remuneration varies over the years due to demand and supply changes in the certificate markets. In these schemes, all renewable technologies thus compete and receive the same level of support (per kWh) (IEA 2004, 2012a, b).

In brief, for our purposes, the solar PV case is motivated, since it is a very promising renewable energy technology, which already plays a key role in the transition to a carbon-free economy. In fact, in recent years, solar PV has been more and more competitive without subsidies in many countries and applications. In this sense, it is a policy success. Still, there have been profound variations in the use and the stringency of policy support across countries and over time, thus permitting a more indepth analysis of the relationship between these policies and innovation.

\subsection{Outline of paper}

In the next section, we briefly present some key theoretical points of departure of the empirical analysis, with a special emphasis on the policy interaction effect. This section also outlines the model specifications as well as the relevant econometric challenges in estimating these models. Section 3 presents the relevant data sources and definitions, including a discussion of the pros and cons of the chosen patent data as innovation proxies. In Sect. 4, we outline the empirical results, including the results from robustness tests. Section 5 discusses and elaborates on the key implications of the empirical results, while Sect. 6 presents some concluding remarks and a number of important avenues for future research. 


\section{Methodological approach and model estimation issues}

\subsection{Theoretical remarks: induced technical change and R\&D-learning interactions}

During the last decades, the economics literature on environmental policy and innovation has devoted increased attention to the role of endogenous technological change and innovation (e.g., Gillingham et al. 2008; Bergek and Berggren 2014). This implies explicitly addressing the feedback mechanisms by which market signals and policy may change the direction of technological change towards cleaner technologies. ${ }^{6}$ The literature suggests that policy may induce innovation in a number of ways, and two main channels of policy-induced innovation can be identified. ${ }^{7}$

The first channel is through policies that facilitate the provision of basic and applied knowledge. Public R\&D support provides knowledge that private companies can appropriate to develop their own technologies, i.e., the support generates knowledge spillovers. Moreover, changing technological opportunities through scientific advancements make additional innovation less costly at a fixed level of demand (Rosenberg 1982). The second channel is through policies that aim to diffuse the targeted technologies and induce various learning processes by "driving down" the technologies' learning curves (e.g., Sagar and Zwaan 2006). Specifically, learningby-doing represents the tacit knowledge acquired during manufacturing, and learning-by-using instead reflects the improvements in the technology as a result of feedback from user experiences.

While demand-pull policies encourage different learning processes, the impacts of different types of schemes may differ. FIT and the REC schemes tend to rely on different conceptions of what nurtures innovation. This relates to the above-mentioned distinction between technology-neutral and technology-specific policies, and whether innovation is spurred by deliberatively making it more vulnerable to competition from the other technologies (Hommels et al. 2007), or whether it, instead, requires the targeted support of protected technological 'niches' (Smith and Raven 2012). REC schemes encourage direct competition among different energy technologies because of the pressures of the bidding process, thus building on the notion that 'selection pressure' is important. The FIT schemes, instead, provide fixed production support for solar PV, and thus, a protected 'nursing market' in which the technology can develop with less direct competition from the other energy sources. As noted above, the choice between technology-neutral and technology-specific

\footnotetext{
${ }^{6}$ This general notion dates back to Hicks (1932), who claimed that a change in the relative prices of two-factor inputs will encourage innovations with the aim to economize on the use of the input which has become relatively more expensive. Popp (2002) and Newell et al. (1999) test this idea empirically on the energy sector.

${ }^{7}$ Innovations leading to the reduction in renewable energy generation costs can possibly spur a tightening of the environmental standards (e.g., Downing and White 1986). Carrión-Flores and Innes (2010) examine this issue by estimating a simultaneous panel data model of environmental innovation and policy stringency, and the findings support the notion of a bi-directional relationship between policy and innovation.
} 
deployment policies likely influences the future risks for premature technological lock-in, e.g., a state in which the energy sector is trapped in one or several specific technologies or systems (Arthur 1989; Unruh 2000). ${ }^{8}$

Finally, demand-pull and technology-push policies may also interact in important ways. The evolutionary economics literature notes that the innovation process is complex, non-linear, and highly iterative (e.g., Foray 2009). The introduction of new technology following R\&D efforts will affect future innovations (the re-development of a technology) through different learning processes and vice versa. An important reason for the existence of such feedback effects is that experiences of the production and use of a technology often lead to the encountering of new problems and the discovery of new opportunities, thus raising the rate-of-return of additional R\&D (Rosenberg 1982; von Hippel and Tyre 1995). In addition, to benefit from learning processes societies must also invest in $\mathrm{R} \& \mathrm{D}$, since it contributes to firms' absorptive capacity, i.e., the ability to recognize and make use of the information generated through learning (Cohen and Levinthal 1990). The above suggests that demand-pull policies that are entirely designed in isolation from R\&D programs could be less effective (Arrow et al. 2009).

Thus, while innovation may be induced directly through the use of single policy instruments, it is important to consider the interactions between demand-pull and technology-push policies. ${ }^{9}$ This conclusion has also been emphasized in a number of solar PV case studies (e.g., Watanabe et al. 2000; Strahs and Tombari 2006; Del Río and Bleda 2012). Hendry et al. (2010) provide empirical examples of R\&D-learning iterations in both the solar PV and wind power sectors. Finally, Costantini et al. (2017) study innovation in energy efficiency technologies, and their results suggest that a balanced policy mix in terms of demand-pull and technology-push policies will improve the innovation performance.

\subsection{Model specifications}

To measure innovative output, we rely on patent application counts. This approach necessitates the use of the so-called count data modeling. Different count data models, using Poisson or negative binomial distributions, have been developed for the estimation of the number of occurrences of an event, or event counts (e.g., Maddala 1983; Cameron and Trivedi 1998). An event count is defined as the realization of a non-negative integer-valued random variable. In our case, an event count corresponds to the number of solar PV patents filed by a given country and time-period.

\footnotetext{
8 Schmidt et al. (2016) emphasize that, in practice, policies typically have different technology-specificity levels, and policy makers are typically faced with choosing the specificity of any deployment policy along two different dimensions: technology and application.

9 Innovative output in a country may also be affected by policies in foreign countries (e.g., Peters et al. 2012; Verdolini and Galeotti 2011). Our focus is, however, on the differential impacts of domestic policies. The influence of foreign demand-pull policies may be limited since technological development often requires a close interaction between users and producers (e.g., Beise-Zee and Rammer 2006). Moreover, the existing research shows little evidence of international policy spillovers in the case of technology-push policies.
} 
Sections 2.3 and 3.1 provide details on the econometric approach and the data sources used, respectively. We first specify two models that do not address any policy interaction. The dependent variable, the total number (counts) of solar PV patent applications $(P C T)$, is assumed to depend on the stringency of the renewable energy support schemes (FIT and REC) as well as on public R\&D support to solar PV (RDEXP and RDSTOCK):

$$
\begin{aligned}
P C T_{i, t}= & \beta_{0}+\beta_{1}\left(\text { FIT }_{i, t}\right)+\beta_{2}\left(\text { REC }_{i, t}\right)+\beta_{3}\left(\text { OILPRICE }_{t}\right)+\beta_{4}\left(\text { TRIPS }_{t}\right) \\
& +\beta_{5}\left(\operatorname{RDEXP}_{i, t-x}\right)+\sum_{i=1}^{n-1} \beta_{5+i} D_{i}+\varepsilon_{i, t} \\
P C T_{i, t}= & \beta_{0}+\beta_{1}\left(\text { FIT }_{i, t}\right)+\beta_{2}\left(\operatorname{REC}_{i, t}\right)+\beta_{3}\left(\text { OILPRICE }_{t}\right)+\beta_{4}\left(\text { TRIPS }_{t}\right) \\
& +\beta_{5}\left(\operatorname{RDSTOCK}_{i, t}\right)+\sum_{i=1}^{n-1} \beta_{5+i} D_{i}+\mu_{i, t} .
\end{aligned}
$$

where $i$ indexes the cross-sectional unit (i.e., country) and $t$ indexes time. In the empirical analysis, we incorporate two ways of measuring the role of public R\&D support. The first specification (Eq. 1) follows the previous work (e.g., Johnstone et al. 2010), and assumes that solar PV patenting activity is influenced directly by annual public $\mathrm{R} \& \mathrm{D}$ expenditures although with a certain time lag $(x)$. This variable is denoted RDEXP. In the second model specification (Eq. 2), we assume, instead, that what matters for solar PV innovation is the build-up of a stock of R\&D-based knowledge over time. Hence, in this approach, annual R\&D expenditures add to this knowledge stock (RDSTOCK) with a time lag, and it is also assumed that knowledge depreciates over time at a certain rate. In Sect. 3, the details of the variable specifications are presented.

The models also include a number of control variables. First, the development of global crude oil prices is important for the electric generation sector as it also will affect the prices of other inputs, such as natural gas and coal. Peters et al. (2012) show that, since the 1970s, crude oil price movements in the world market have been a key determinant of the interest in improving the performance of solar PV technology. For this reason, our model specifications include the variable OILPRICE, i.e., the global crude oil price in real terms. This variable is common for all countries in the sample (i.e., it is time-specific), but of course varies over time.

Moreover, the characteristics of intellectual property rights regimes may have a significant influence on the propensity to seek property rights protection rather than relying on some other means to protect intellectual property (e.g., industrial secrecy). For this reason, the binary variable TRIPS is included to control for the so-called TRIPS agreement signed in 1994. This regulates the traderelated aspects of intellectual property rights. This agreement was signed by the WTO member countries, including all of the countries included in our sample, potentially making it easier and more meaningful for innovators to apply for 
patents (not least in other countries). Finally, country-specific dummy variables $\left(D_{i}\right)$ have been included in both model specifications to control for fixed effects attributed to unobserved factors such as regulatory framework, domestic patenting rules and traditions, etc. All residual variation in the two models is captured by the additive error terms $\left(\varepsilon_{i, t}\right.$ and $\left.\mu_{i, t}\right)$.

To address the potential policy interaction between public R\&D and the two different solar PV production support schemes, we also consider two additional model specifications. Specifically, we multiply RDEXP and RDSTOCK, respectively, with two discrete dummy variables indicating whether an FIT or an REC scheme, respectively, has been in place for each country and time-period. This gives us the following alternative model specifications, again differing with respect to the way in which public R\&D support has been operationalized:

$$
\begin{aligned}
P C T_{i, t}= & \beta_{0}+\beta_{1}\left(\text { FIT }_{i, t}\right)+\beta_{2}\left(\text { REC }_{i, t}\right)+\beta_{3}\left(\text { OILPRICE }_{t}\right)+\beta_{4}\left(\text { TRIPS }_{t}\right) \\
& +\beta_{5}\left(\operatorname{RDEXP}_{i, t-x}\right)+\beta_{6}\left(\text { EXPFIT }_{i, t}\right)+\beta_{7}\left(\text { EXPREC }_{i, t}\right)+\sum_{i=1}^{n-1} \beta_{7+i} D_{i}+\pi_{i, t} \\
\text { PCT }_{i, t}= & \beta_{0}+\beta_{1}\left(\text { FIT }_{i, t}\right)+\beta_{2}\left(\text { REC }_{i, t}\right)+\beta_{3}\left(\text { OILPRICE }_{t}\right)+\beta_{4}\left(\text { TRIPS }_{t}\right) \\
& +\beta_{5}\left(\text { RDSTOCK }_{i, t}\right)+\beta_{6}\left(\text { EXPFIT }_{i, t}\right)+\beta_{7}\left(\text { EXPREC }_{i, t}\right)+\sum_{i=1}^{n-1} \beta_{7+i} D_{i}+\phi_{i, t} .
\end{aligned}
$$

The interaction variables are denoted EXPFIT and EXPREC, respectively. These alternative model specifications can be employed to test the null hypothesis that the impact of a marginal increase in public R\&D support to solar PV has the same impact on patenting activity regardless of whether an FIT and/or an REC scheme have been present. Finally, $\pi_{i, t}$ and $\phi_{i, t}$ are additive error terms.

To sum up, the empirical analysis is based on four model specifications, hereafter denoted S1-S4: (a) no policy interaction effects and public R\&D support measured through lagged R\&D expenditures (S1); (b) no interaction effects and public R\&D support measured through an R\&D-based knowledge stock (S2); (c) interaction effects and lagged $R \& D$ expenditures (S3); (d) interaction effects and the R\&D-based knowledge stock (S4). In addition, we also conduct a number of robustness tests, e.g., with respect to the specific operationalization of the independent variables, the approach used to calculate the standard errors, the choice of sample countries, and the presence of time effects, etc. These tests are elaborated on below.

\subsection{Econometric issues}

Count data estimators are generally used to fit models where the dependent variable has a count nature. However, patent count data are generally overdispersed, thus, meaning that the variance exceeds the mean. In this study, a negative binomial (NB) 
estimator is, therefore, used this, since it can accommodate this issue (Hilbe 2011). The NB estimator has also been used in the related work (e.g., Johnstone et al. 2010; Rübbelke and Weiss 2011).

A number of different NB models have been developed, and those most commonly used to accommodate overdispersion are the so-called NB1 and NB2 models (Cameron and Trivedi 1998). ${ }^{10}$ Allison and Waterman (2002) analyze the performance of different fixed-effects NB models, and conclude that the conditional-fixed-effects NB1 model proposed by Hausman et al. (1984) is not a true fixed-effects estimator. Guimarães (2008) re-asserts these results by demonstrating that this model does not control for country-specific effects unless particular suppositions are met. Moreover, by conducting a simulation experiment, Allison and Waterman (2002) and Greene (2004) find that the unconditional NB model (i.e., a conventional NB2 model with dummy variables to address the fixed effects) performs well, even though this model is accompanied by downward bias in the standard error estimates.

In the light of this, we rely on the unconditional NB model. To adjust for any potential bias in the standard error estimates, bootstrapped standard errors stratified by country are computed. This has been suggested by both Hilbe (2011) and Cameron and Trivedi (1998) when employing small samples. However, since this may not properly account for serial correlation within countries, we also present results using robust standard errors clustered at the country level. All model specifications are estimated using Stata 12 and a modified Newton-Raphson algorithm (i.e., the default setting when employing maximum-likelihood estimation).

Since we include the time-specific OILPRICE variable, we do not explicitly control for other time-specific effects (using yearly dummy variables). This is a potential problem, though, since the estimated policy coefficients may also capture any macroeconomic shocks correlated with both the levels of the policies and patenting activity (Popp et al. 2011). Although we already address the most important common shock, the crude oil price development, we also estimate some alternative models to check the robustness of our results. First, we follow Peters et al. (2012) who also do not include yearly dummies but instead control for three time-periods in the development of solar PV patents. They note that this development can be subdivided into three distinct phases: boom (1974-1985), stagnation (1986-1994), and boom (1995-2009). In our estimations, we include dummy variables for the last two periods. ${ }^{11}$ Second, we also test the models including year-specific dummy variables to control for common unobserved shocks, in this case excluding both the crude oil price and the two time-period dummies. The results from the robustness tests are commented in Sect. 4.2.

\footnotetext{
10 These two models are based on different variance functions. The NB1 model specifies that the variance of the dependent count variable is equal to a multiple of the mean, while the NB2 variance is quadratic in the mean. Different standard error estimates are thus generated by the models, and the most common implementation is the NB2 model (Cameron and Trivedi 1998).

11 In the time-period estimations, we exclude the TRIPS variable, since it almost exactly coincides with the dummy for the third period.
} 


\section{Data sources and definitions}

The empirical analysis builds on an unbalanced panel data set covering 13 countries over the time-period 1978-2008. The panel data set is limited to 2008 due to the delays in the publishing of patent information, but also since we are here primarily interested in the policy challenges in supporting immature technologies. The chosen countries include Austria, Belgium, Denmark, France, Germany, Italy, Japan, the Netherlands, South Korea, Spain, Sweden, Switzerland, and the United Kingdom (UK).

This focus of this paper on the policy impacts on solar PV innovations implies that the choice of countries has been influenced by the availability of reliable data in this respect. The absence of detailed data on FIT and REC levels over a longer timeperiod has ruled out a number of countries. In fact, our interest in addressing policy interaction also implies a need for periods characterized by the absence of demandpull instruments. However, we have made deliberate efforts to obtain a balanced sample consisting of both the most progressive countries in the solar PV field (e.g., Germany, Japan, etc.), and of countries with less-developed solar PV sectors (e.g., Austria, Belgium, and Sweden). ${ }^{12}$ Finally, countries with several independent states employing their own demand-pull policies, e.g., the USA, are difficult to include due to the intermingling of federal and state levels.

\subsection{The dependent variable: solar PV patent counts}

To measure solar PV innovations, we have extracted data from the OECD Statistics Database (2013) related to patent applications filed under the so-called Patent Cooperation Treaty (PCT). In line with the recommendations of OECD (2009), the PCT applications are sorted by inventor country of residence and priority date, and the total number of applications are rounded to the nearest integer (patents specifying multiple inventor countries were partly attributed to each country by the use of fractional counts). In contrast to Johnstone et al. (2010), we employ a purer patent category, and focus solely on solar PV. This means that we consider patent categories concerning: (a) PV systems with concentrators; (b) PV material technologies; (c) power conversion. ${ }^{13}$

Patent counts are probably the most suitable innovation proxy compared to the other indicators available, such as R\&D expenditures and counts of scientific personnel. One important reason for this is that patents are an output measure of innovative activity as opposed to, for instance, $R \& D$ expenditures that serve as inputs to such activities (Johnstone et al. 2010). In addition, patents have a close link to

\footnotetext{
12 To provide some tests for the existence of country selection bias, we also re-estimated the models after removing countries (e.g., South Korea) with a relatively large number of missing observations (see also Sect. 3.2). These results show that the overall results are robust to this omission.

13 The following patent classes are contained in these categories expressed in European Classification (ECLA) code: Y02E 10/52 (PV systems with concentrators), Y02E 10/541-546, 10/548 (PV material technologies), and Y02E 10/56 (power conversion, electric or electronic aspects).
} 
inventions, since each document contains information about the applicant, the inventor, and the invention, and this enables detailed statistical analysis (OECD 2009). However, using patent counts to approximate innovative activity is also associated with a number of problems: (a) not all inventions are patented; (b) the value distribution of patents is highly skewed; (c) there are differences in patent regimes and patent propensity across countries and over time (e.g., Schankerman 1998; Jaumotte and Pain 2005; OECD 2009). Schmoch (1997) notes, though, that patent counts are positively correlated with non-patented inventive activity, and this mitigates the issue posed in (a). Moreover, measuring innovation with PCT applications mitigates the issue posed in (b), since a significant fee is attached to the examination of a PCT application (and that fee is higher than that of a domestic application). Protection is thus sought once the prospects of commercialization are regarded as favorable by the applicant. Using PCT data also limit the issue posed in (c) as applications are not compiled across a number of patent offices with different rules and practices. ${ }^{14}$

Still, our patent data set also has limitations. In particular, as noted above, our prime focus is on PV systems as well as novel cell and module designs. In other words, the emphasis is on product innovation, and the data set does not cover process innovation (or at least very little of this). This is of course an important limitation given the fact that equipment innovation has largely been responsible for driving down the cost of solar PV (Huenteler et al. 2016). Still, the chosen focus is motivated in part by the fact that we position our paper in relation to the studies by Johnstone et al. (2010) and Peters et al. (2012), and these have similar (albeit not identical) approaches to solar PV patent data selection (see also the recent paper by Comins and Leyersdorff 2018). Furthermore, the purpose of our paper is not to investigate the determinants of observed cost reductions, but, instead, the statistical correlation between various policies and patenting activity in the solar PV field. In line with Dechezleprêtre et al. (2011), it is reasonable to assume that "all innovation in a given field follows a similar trend. Hence, at the worst, our data set can be seen as being a good proxy of innovative activity in the technology fields considered," (p. 114) (see also Peters et al. 2012). Public policies that support the development of solar PV will induce both process and product innovation, the two spurring each other.

\footnotetext{
${ }^{14}$ As pointed out by an anonymous referee, other patent indicators commonly employed are applications filed to the European Patent Office (EPO) and patent family counts (e.g., triadic patent families). We have opted for PCT applications, since EPO data: (a) suffer from relatively long publication delays (since the beginning of the 2000s, a large share of the EPO applications are filed at the EPO with PCT pre-application) (e.g., Frietsch and Schmoch 2010), and (b) tend to be biased towards applications from European inventors (generally referred to as 'home advantage bias') (e.g., OECD 2009). Moreover, while triadic patent families available in the OECD Statistics Database are relatively free from home advantage bias, these data are incomplete after 2004 due to delays in the publication of patent information. Still, distinguishing between the different indicators is not straightforward as EPO applications and PCTs often are the members of patent families protecting inventions in different countries or regions around the world. It is also difficult to distinguish between EPO applications and PCTs as the majority of the EPO applications originate from the PCT procedure since the beginning of the $2000 \mathrm{~s}$ (referred to as Euro-PCTs) (e.g., OECD 2009).
} 
Figure 1 displays the PCT data for the sample countries in terms of the number of solar PV patent applications, and their share of the total number of PCT applications (filed over all technological areas). The data indicate that solar PV patenting activity has increased rapidly since the beginning of the 1990s. The same trend can be observed for the share of solar PV patents in relation to all patent applications. However, there are also significant differences across the sample countries. For instance, since the mid-1990s, patent applications in Japan and Germany increased at a relatively high rate, making these countries the most prominent in solar PV patenting activity during the studied period. The remaining countries in the sample did not experience a similar take-off, and most of them saw their solar PV patent applications increase only in the beginning of the 2000s. Among these, the UK, South Korea, France, and Italy stand out with the highest number of applications while the figures for Sweden, Denmark, and Austria display no clear positive trend.

\subsection{The independent variables}

The independent variables in our models can be divided into three main categories: (a) policy variables; (b) policy interaction variables; (c) a set of control variables. The first category includes different measures of the level of support to solar PV either through feed-in tariff (FIT), renewable energy certificate (REC) schemes or public R\&D expenditures. In the FIT case, we have collected data on the total remuneration granted per unit of electricity generated with solar PV. Specifically, the FIT variable measures the annual tariff levels in US cents per kWh (in 2005 prices), and the data used to construct this variable were obtained from IEA (2004, 2012a, b), Cerveny and Resch (1998), Gipe (2013) and various country-specific sources. ${ }^{15}$ For most countries that have implemented this policy, the schemes specify a fixed total tariff over a certain time-period, while in a few cases, the schemes involve a premium above the (variable) market retail price for electricity. In the latter cases, we include both the market price and the premium. In the case of REC schemes, we follow Johnstone et al. (2010) and measure policy stringency as the percentage of total electricity use that must be generated by renewable energy sources (including solar PV). These data were obtained from the IEA (2004, 2012a, b) and various countryspecific sources.

While this specification of the FIT, variable is more detailed than that used in many other studies (such as Peters et al. 2012), there are several policy design features that we are not able to take into account. This concerns, for instance, the fact that some countries (e.g., Germany) have not capped their FIT budgets, while others have. Such differences could result in different market sizes, in turn, affecting the incentives to innovate. Another design issue concerns the time-period during which the support is available. Still, while the duration of guarantees of FIT support may differ across a few of the countries, there is some amount of guarantees over a

\footnotetext{
15 The FIT data were taken as nominal currency for the year of the publication or legislation and were deflated (to 2005 prices) using the consumer price index. These figures were then converted to the US cents using the market exchange rates.
} 
certain period, thus limiting the amount of investor uncertainty (e.g., Couture and Gagnon 2010). Moreover, the FIT schemes also differ in the sense that some provide a fixed total remuneration to solar PV investors, while others instead specify a price premium above the price in the wholesale market for electricity. The former dominates our sample. In our empirical investigation, we treat these two schemes as identical, but they are not. The former fully removes the price risk, whereas price premiums only provide revenue without removing risk.

A particularly important design issue is the use of time-declining FIT levels to address the cost dynamics of the technology. In the case of solar PV modules, Reichelstein and Sahoo (2018) report the evidence of substantial technological learning. Solar PV costs have also decreased due to falling material (e.g., silicon) prices. More innovation and falling prices imply less need for maintaining high FIT levels. The ideal approach would be to measure the difference between the FIT level and the levelized cost of energy, but our FIT variable only accounts for the initial (year one) support. It should be noted, though, that our data sample covers a period of solar PV innovation during which this technology was relatively immature. For this reason, such policy adjustment is not prevalent in the sample, although one important exception is Germany where time-declining FIT levels were introduced already in 2000 (e.g., Hoppman et al. 2014). In more recent years, the FIT levels for solar PV have decreased in many countries (e.g., de la Tour et al. 2013). Addressing the above policy design issues should constitute an important area for future research (see also Sect. 6).

Furthermore, in investigating the role of policy on innovation activities, we need to address the relevant time lags following the implementation of - or changes inthe FIT and REC schemes.

Clearly, patenting activities will lag changes in these policies. At the same time, though, solar PV investors are made aware of such changes well in advance of their implementation. For this reason, the policy changes may induce significant innovation efforts already at the time of such announcements. The implicit assumption in this paper is that these two effects cancel out, i.e., we assume to observe policyinduced patenting activities already during the year at which the policy has been put into place (see also Nicolli et al. 2012).

Figure 2 shows the introduction of FIT and REC schemes, respectively, in the sample countries over the 1978-2008 period. Some of the countries introduced an FIT scheme already during the 1990s, while all the REC schemes were introduced after the turn of the century. Overall, FIT schemes have been more prevalent in the solar PV field than have REC schemes. ${ }^{16}$ Over the period, the average FIT support in real US cents per $\mathrm{kWh}$ has increased from around US 2 cents in 1991 to about US 31 cents in 2008. As noted above, this average does not account for time-declining rates in a few countries, and it is only based on countries with the existing FIT policies.

\footnotetext{
16 Over the time-period, five countries have introduced REC schemes, implying that we include 25 observations containing REC targets larger than zero. There is thus some variation to exploit empirically also in these data.
} 


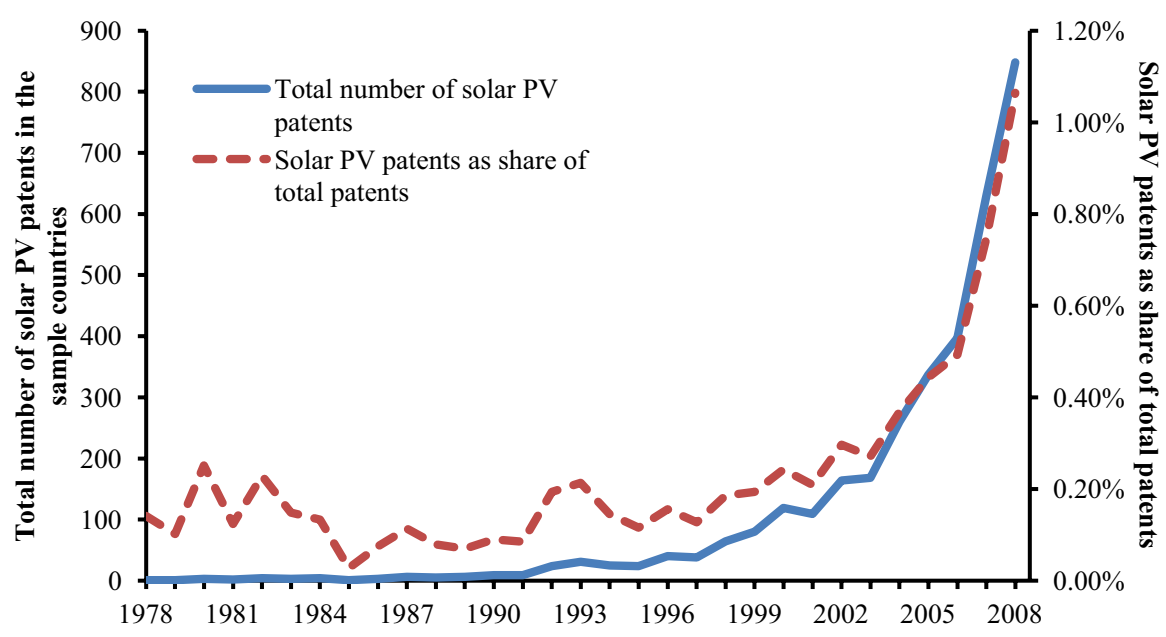

Fig. 1 Solar PV patent applications (PCT) in the sample countries, 1978-2008. Source: OECD (2013)

Public support to solar PV R\&D is another key policy variable, and we introduce two different ways of measuring the impacts of this policy. ${ }^{17}$ Both measures were constructed by employing annual public R\&D expenditure data (million US dollars in 2012 prices) from the IEA (2013). ${ }^{18}$ These data exclude subsidies to private companies, so the main way in which public R\&D can induce patenting activity is by providing new knowledge that private companies can use to develop their own technologies (i.e., knowledge spillovers). In model specifications S1 and S3, we include a variable measuring public R\&D expenditure to solar PV with a 2-year time lag (e.g., Braun et al. 2010). In other words, this specification assumes that public R\&D efforts cannot instantaneously result in more patent applications.

Figure 3 shows the development of public support to solar PV R\&D (without any time lag), and aggregated over all 13 sample countries for the time-period 1978-2008. Following the oil crises in the 1970s, several of the sample countries increased their energy R\&D budgets, often with a strong emphasis on renewable energy sources (Rübbelke and Weiss 2011). In the mid-1980s, public R\&D support to solar PV decreased, but began to increase again from the mid-1990s and onwards. This supports the approach of Peters et al. (2012) to subdivide solar PV development into three periods of boom, stagnation, and boom. Over the entire period, public R\&D support was the highest in Germany and Japan but relatively generous

\footnotetext{
${ }^{17}$ Public R\&D may be endogenous if publicly developed patents are included in the dependent variable. We are, however, unable to distinguish between private and public patents in our data set. Still, de la Tour et al. (2011) reported that about $85 \%$ of the solar PV patents in the OECD countries have been privately developed.

${ }^{18}$ The IEA database covers public expenditures on demonstration activities in addition to R\&D. However, the contents of the database are heavily biased towards the latter, thus, making it suitable to consider the data as mainly related to R\&D (Wiesenthal et al. 2009).
} 


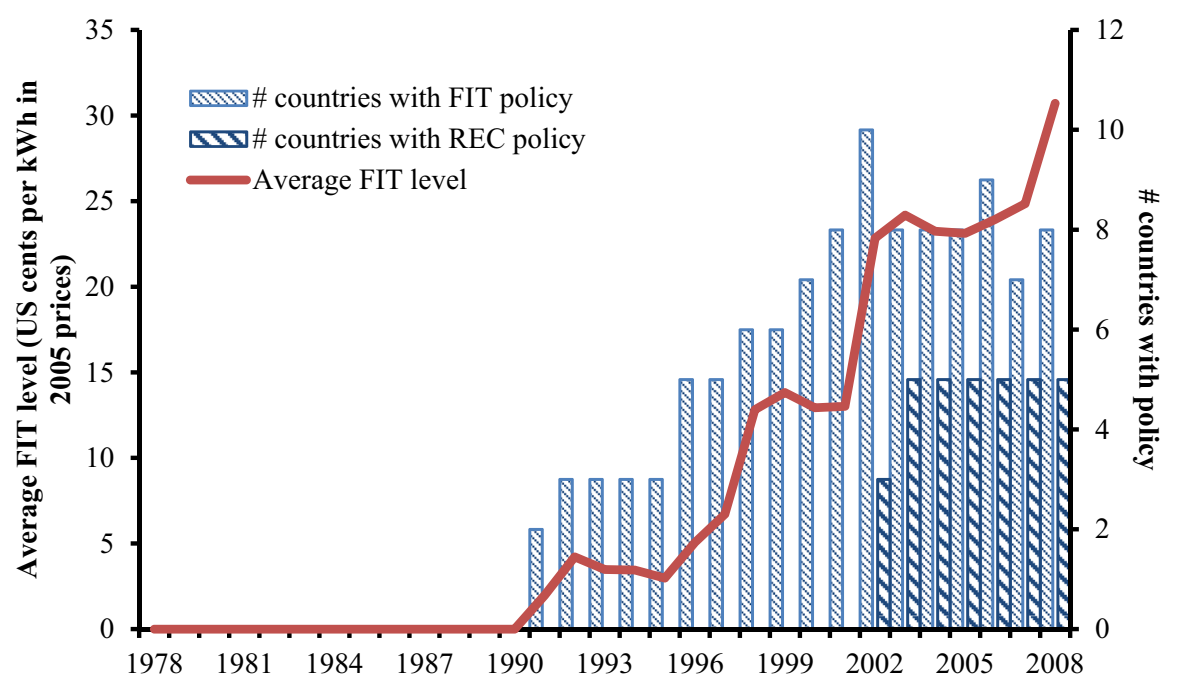

Fig. 2 Level of FIT support and the introduction of FIT and REC schemes, 1978-2008. Sources: IEA (2004, 2012a, b), Cerveny and Resch (1998), Gipe (2013) and various country-specific sources

support was also provided in Italy, the Netherlands, and Switzerland. Interestingly, when considering the entire time-period, public R\&D support levels in the respective sample countries have been relatively stable. Still, the data for France, Germany, Italy, Korea, and the UK display an increasing trend during the 2000s.

Model specifications S2 and S4 instead build on the notion that the previous R\&D expenditures add to an R\&D-based knowledge stock (e.g., Klaassen et al. 2005; Ek and Söderholm 2010). We have:

$$
\operatorname{RDSTOCK}_{i, t}=(1-\delta) \operatorname{RDSTOCK}_{i, t-1}+\operatorname{RDEXP}_{i, t-x},
$$

where $i$ indexes the sample countries, and $t$ indexes time. In this equation, RDSTOCK is the R\&D-based knowledge stock for solar PV in country $i$ and timeperiod $t, R D E X P$ are the annual public R\&D expenditures, $x$ is the number of years that it takes before $R \& D$ expenditures add to the knowledge stock, and $\delta$ is the annual depreciation rate of the knowledge stock $(\delta \in[0,1])$. In other words, this formulation takes into account that: (a) public R\&D support to solar PV does not have an instantaneous effect on the generation of new knowledge, but will only lead to tangible results after some years have lapsed; (b) knowledge depreciates in that the effects of previous public R\&D expenses gradually become outdated (see also Griliches 1995).

To construct the knowledge stock variable, in the baseline case, we assume a time lag of 2 years $(x=2)$, and a depreciation rate of $10 \%(\delta=0.10)$. This choice of time lag is constrained by the limited data set. Popp (2015) shows that the time lag between public R\&D and private energy patents can often be extensive. Still, in the case of solar energy technology, relatively shorter lags may suffice, and he reports a large increase in the cumulative effects between years 3 and 4 . 


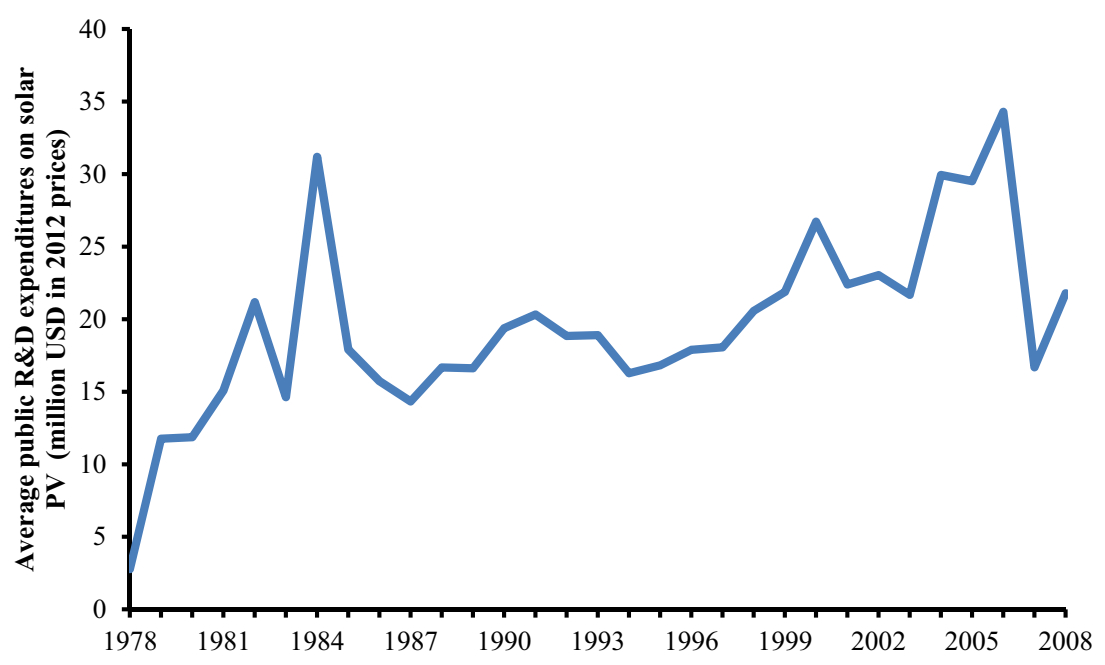

Fig. 3 Public R\&D expenditures on solar PV in the sample countries, 1978-2008. Source: IEA (2013)

However, he also argues that lags up to 6 years may have to be considered. Furthermore, our choice of a $10 \%$ discount rate suggests a fairly high rate of depreciation of R\&D-based knowledge (e.g., Griliches 1995; Nordhaus 2002), but this is in part reflected in the relatively rapid development of renewable energy technology, since the oil crises in the 1970s (McVeigh et al. 2000). Given the uncertainties inherent in these parameter assumptions, we, therefore, also conduct sensitivity analyses investigating the consequences of using alternative depreciation rates and time lags, respectively. Nevertheless, the relevance of these assumptions deserves the further research.

The IEA provides public R\&D data for solar PV from the year 1974. In this year, the respective domestic $R \& D$ expenses were close to zero. These low figures represent our initial conditions when constructing the domestic R\&D-based knowledge stocks. For instance, the knowledge stock in 1990 for a given country is a function of the annual public R\&D expenditures on solar PV during the time-period 1974-1988, and with the depreciation rate attached to the stock.

Our two policy interaction variables investigating the relationship between public R\&D and the FIT and REC schemes, respectively, draw from the same IEA (2013) data. The interaction variables were constructed as the product between the R\&D variables and dummy variables taking the value of one (1) if an FIT and REC scheme is in place (and zero (0) otherwise). The motive behind this simple specification is that the feedback effects from the different learning processes to public R\&D are likely to be complex. For instance, the learning taking place may be subject to diminishing returns and, perhaps, to threshold effects in a manner that is difficult to specify ex ante. There may also be important differences across countries with sometimes limited learning feedbacks beyond certain levels of production. Thus, we 
see a little reason to impose a less flexible specification assuming, for instance, a linear relationship, so that a given increase in public R\&D support would lead to more innovation activity in a way that closely follows the domestic production of solar PV. ${ }^{19}$

Finally, all four model specifications (S1-S4) include a number of control variables. First, we introduce a dummy variable taking the value of one (1) to address the enforcement of the so-called TRIPS agreement in 1995. In this way, we control for the agreement's potential effect on the propensity to patent. ${ }^{20}$ Second, data on the development of international crude oil prices have been collected from IEA (2015), and this variable is expressed in USD per barrel (bbl) in 2010 prices. The country-specific dummy variables can be assumed to control for, for instance, differences in overall patent propensities and the regulation of immaterial property rights. To avoid perfect collinearity, the dummy variable for Germany was omitted from the estimations, and Germany is, thus, the reference category in all regression models.

Table 1 summarizes the variables employed in the empirical investigation, and provides some descriptive statistics for each of these. Table 5 shows the correlation rates for the independent variables in the sample, essentially showing that these rates are overall low. The highest rates are found between the interaction variables and the $R \& D$ variables, ranging between 0.28 and 0.61 . The $S 2$ model specification was estimated using a total of 352 observations, while the remaining models build on the use of 350 observations (due to a couple of missing observations for the RDEXP variable). The descriptive statistics in Table 1 are based on the 350 observations used to estimate S1, S3, and S4. In addition, the models included country-specific effects and different ways of dealing with common time-specific shocks (see further below).

In a few cases, observations were missing for $R \& D$ expenditures, and this was dealt with by replacing the missing observations with means based on the adjacent values. This was, however, only a problem for single observations in three countries (Italy, Spain, and Belgium). In the case of South Korea, a range of seven observations was missing. For our main specifications, these observations were disregarded. However, as noted above, we also estimated all the models after having removed South Korea from the sample. The results were robust to this omission.

\footnotetext{
${ }^{19}$ We also tested interacting the R\&D variables with the continuous $F I T$ variable, but the results indicated no statistically significant effect for this alternative interaction variable. Nevertheless, due to high country-specific correlation rates between the two R\&D variables and this particular interaction term (ranging between 0.89 and 0.97), it is difficult to draw any solid conclusions based on these results. As noted below (see also Table 5), the correlation rates between the chosen interaction variables and the other dependent variables were substantially lower.

${ }^{20}$ The number of patent applications rose significantly on a global level between the mid-1990s and the mid-2000s, in part as a result of the signature of the TRIPS agreement in 1994 (OECD 2009). As was noted above, this was because the TRIPS agreement made it easier and more meaningful for innovators to apply for patents (also in the other countries), and not because it improved the strength of intellectual property protection.
} 


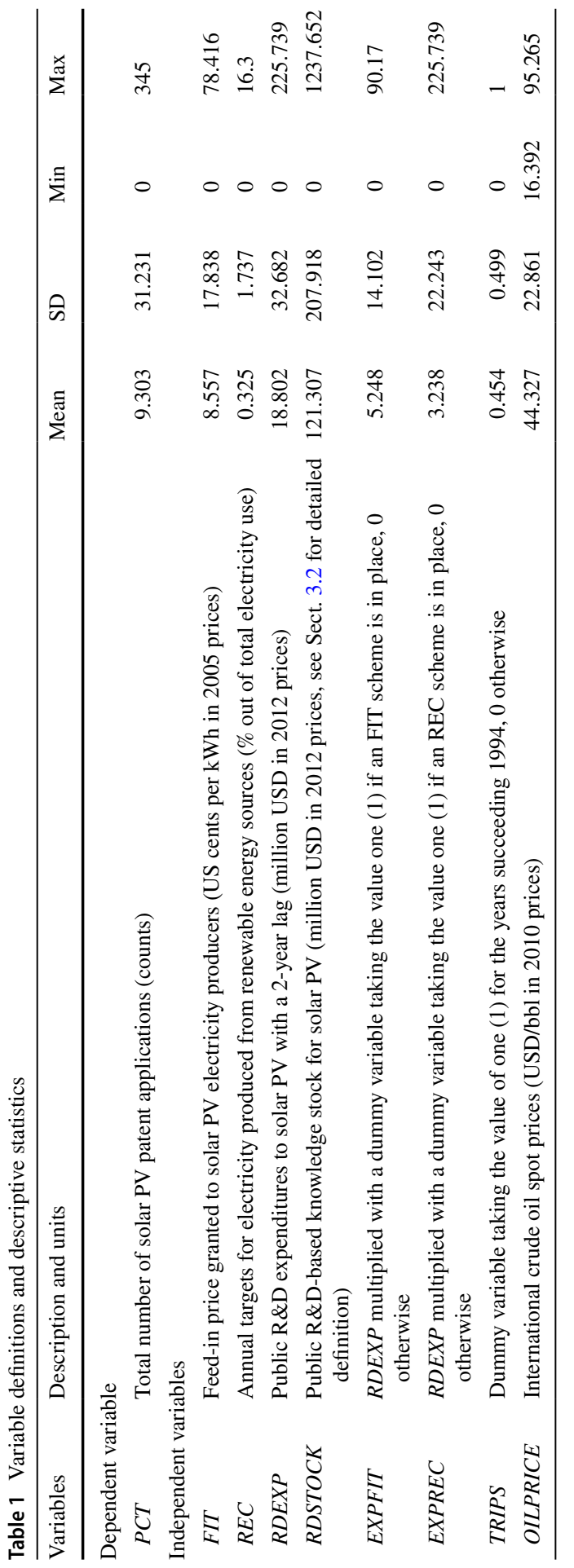


Table 2 Estimation results from the negative binomial models with country-specific effects

\begin{tabular}{|c|c|c|c|c|}
\hline & $\mathrm{S} 1$ & $\mathrm{~S} 2$ & S3 & $\mathrm{S} 4$ \\
\hline \multicolumn{5}{|l|}{ Control variables } \\
\hline OILPRICE & $0.012 * * *(0.002)$ & $0.014 * * *(0.000)$ & $0.014 * * *(0.000)$ & $0.016 * * *(0.000)$ \\
\hline TRIPS & $2.318 * * *(0.000)$ & $1.970 * * *(0.000)$ & $2.405 * * *(0.000)$ & $2.118 * * *(0.000)$ \\
\hline \multicolumn{5}{|l|}{ Public policies } \\
\hline$F I T$ & $0.023 * * *(0.000)$ & $0.019 * * *(0.000)$ & $0.017 * * *(0.007)$ & $0.013 * *(0.023)$ \\
\hline$R E C$ & $0.093 * *(0.010)$ & $0.103 * * *(0.005)$ & $0.085 * *(0.018)$ & $0.093 * *(0.010)$ \\
\hline$R D E X P$ & $0.021 * * *(0.000)$ & - & $0.013 * * *(0.001)$ & - \\
\hline RDSTOCK & - & $0.004 * * *(0.000)$ & - & $0.003 * * *(0.000)$ \\
\hline \multicolumn{5}{|l|}{ Policy interaction } \\
\hline EXPFIT & - & - & $0.019 * * *(0.009)$ & $0.019 * *(0.018)$ \\
\hline EXPREC & - & - & $0.004(0.333)$ & $0.000(0.918)$ \\
\hline Log-likelihood (NB) & -628.104 & -623.606 & -619.973 & -615.436 \\
\hline Log-likelihood (Poisson) & -825.172 & -806.821 & -812.110 & -796.330 \\
\hline \multirow{2}{*}{$\begin{array}{l}\alpha \text { (overdispersion param- } \\
\quad \text { eter) }\end{array}$} & 0.403 & 0.356 & 0.349 & 0.317 \\
\hline & s.e. 0.096 & s.e. 0.086 & s.e. 0.079 & s.e. 0.071 \\
\hline$x^{2}$ & 968.04 & 1080.85 & 934.39 & 1010.35 \\
\hline$p>x^{2}$ & 0.000 & 0.000 & 0.000 & 0.000 \\
\hline$N$ & 350 & 352 & 350 & 350 \\
\hline
\end{tabular}

$p$ values in parentheses (based on bootstrapped standard errors stratified by country); $* p<0.10$; $* * p<0.05 ; * * * p<0.01$. Stata automatically provides the log-likelihood of fitting a Poisson model. This statistic is necessary when conducting a likelihood-ratio overdispersion test

\section{Empirical results}

\subsection{Estimation results from the negative binomial model specifications}

Table 2 presents the regression results of the four model specifications using the negative binomial model (NB2) with bootstrapped standard errors stratified by country and country-specific fixed effects. ${ }^{21}$ In terms of overall model performance, it can be noted that the Newton-Raphson algorithm converged to a maximum after relatively few iterations for all model specifications (7-9 iterations were required for fitting each specification). In addition, a concave (marginally declining) convergence path could be observed. This suggests that all four log-likelihood functions are well behaved (Gould et al. 2006). Moreover, all model specifications are statistically

\footnotetext{
${ }^{21}$ The accuracy of the bootstrap estimate (the bootstrap distribution) in part depends on the number of bootstrap replications. For this reason, we ran all four models (S1-S4) using both 200 and 5000 replications as a robustness check. The results indicated only small differences with respect to the bootstrapped standard errors, and the results in Table 2 are based on the use of 5000 replications. In Table 6 in the "Appendix", we report our results based on the computation of robust standard errors clustered at the country level. These standard errors are only marginally different from the bootstrapped ones in Table 2. This does, therefore, not alter any of the main conclusions.
} 
significant according to the $p$ values associated with the Wald Chi-square statistics, thus rejecting the null hypothesis that all of the estimated coefficients equal zero. Likelihood-ratio tests and Wald tests were conducted, and both reject the null hypothesis of equidispersion for all specifications (i.e., that the overdispersion parameter is equal to zero).

The empirical results in Table 2 indicate that public policy has been a major driver of solar PV patents in the sample countries. Increases in feed-in tariff (FIT) and renewable energy certificate (REC) support levels, respectively, as well as increases in public R\&D support have implied more fertile ground for innovation. The results also show that some policy interaction is present in that a given increase in public R\&D support will (ceteris paribus) tend to have a stronger impact on patenting activity when the policy is accompanied by an FIT scheme for solar PV. The crude oil price and the TRIPS agreement have also been important determinants of solar PV patenting activity. ${ }^{22}$ However, while Table 2 provides useful information about the signs of the relevant impacts, they do not lend themselves to any meaningful interpretation of the economic significance (size) of these impacts. The estimated coefficients can formally be understood as the difference between the natural logarithms of expected counts (e.g., Hilbe 2011).

To avoid this interpretation in log-counts and instead assess the differential effects of the independent variables, we compute elasticities by taking $\hat{\beta}_{j} \bar{x}_{j}$ which is a measure of the elasticity of $E[y \mid x]$ with respect to $x_{j}$ (i.e., the $j$ th regressor) (see Cameron and Trivedi 1998). The resulting elasticities are presented in Table 3, and they can be interpreted as the percentage change in solar PV patenting activity following a $1 \%$ change in the relevant independent variable. All but two of these elasticities are statistically significant (at the $10 \%$ significance level or lower). In the S3 and S4 model specifications, the elasticities for the interaction variable that address the relationship between public solar PV R\&D expenditures and REC schemes are statistically insignificant.

The estimated elasticities in Table 3 confirm the positive relationship between different public policies, the crude oil price and the TRIPS agreement on one hand, and solar PV patenting activities on the other. Still, the economic significance of the different independent variables differs in important respects. For instance, it is worth noting that the changes in the crude oil prices appear to have had positive effects on patent applications in solar PV, and this impact has been considerable. A $1 \%$ increase in OILPRICE has induced a $0.53-0.71 \%$ increase in solar PV patents (depending on model specification). This supports the conclusion of many previous studies (e.g., Peters et al. 2012), stating that the interest in solar PV innovation activity has been correlated with oil price developments. Table 3 also shows that all

\footnotetext{
22 Johnstone et al. (2010) also include the price of electricity, and they report a statistically significant and positive correlation between this price and the patent counts for solar energy. In our model specifications, though the FIT variable includes the total remuneration to solar PV production (i.e., the retail market price of electricity plus any premium), thus, making the inclusion of the electricity variable redundant. As a robustness check, we included the electricity price in our models (using the same IEA source as Johnstone et al. 2010), but the associated coefficients were highly statistically insignificant, and the inclusion of this variable also had negligible effects on the remaining parameter estimates.
} 
in all public policy, both in terms of production support schemes and in terms of public R\&D expenditures, has had profound impacts on solar PV patenting activity. Initially, we focus on the results from the S1 and S2 model specifications (with no policy interaction effects).

The results suggest that the levels of support provided through both FIT and REC schemes have had positive impacts on patent applications. However, since the relevant elasticities are based on different metrics, we cannot compare the respective impacts without additional calculations. We, therefore, calculate the shadow price of the REC target, and then identify what percentage increase in this target that corresponds to a $1 \%$ increase in price support. To do this, we use Johnson's (2014) estimate of 2.67 for the own-price elasticity of supply of renewable electricity generation. When multiplying our estimated REC elasticities with 2.67 , we obtain the percentage change in PV patent counts following a $1 \%$ increase in the price (per $\mathrm{kWh}$ ) needed to attain the REC quota. For instance, in all models, the elasticities of REC quotas equal 0.03 (Table 3), thus suggesting that, if the shadow price of renewable electricity increases by $1 \%$, PV patent applications will increase by $0.08 \%$. This is consistently lower than the corresponding FIT elasticities, which range between 0.11 and $0.20 .^{23}$ These results suggest, therefore, that, in the solar PV case, the FIT schemes have been more innovation-promoting than REC schemes.

Finally, Table 3 shows that the role of public R\&D support for solar PV innovation is also found to be important. The S1 and S2 model specifications differ in the way that the R\&D impacts are operationalized, but both indicate positive (lagged) impacts of public R\&D support on solar PV patent counts. Moreover, the role of public $\mathrm{R} \& \mathrm{D}$ is found to be more economically significant for solar PV patenting activity than that of the two different production support schemes (not the least the REC scheme). ${ }^{24}$

In model specifications S3 and S4, we also test the notion that there could exist important interaction effects between the two different policy categories (public R\&D expenditures and the two production support schemes, respectively). The results in Tables 2 and 3 suggest that we can reject the hypothesis of no interaction effects between public R\&D and FIT schemes. Specifically, a marginal increase in

\footnotetext{
${ }^{23}$ Clearly, these calculations suffer from a number of uncertainties. However, they also illustrate that the elasticity of renewable electricity supply need to be very high in order for the REC elasticities to be on par with the FIT elasticities. As an illustration of this, we can note that Johnson (2014) also reports a $95 \%$ confidence interval for the elasticity at 1.74-3.60. If the calculations are repeated but now using the upper limit in this confidence interval (3.60), the overall conclusion still holds-FIT schemes are more innovation-promoting than the REC schemes. Indeed, the own-price elasticity of renewable electricity (and solar PV) supply would need to be as high as 5.00 for the REC impact to be on par with the FIT impacts.

24 The construction of the R\&D-based knowledge stock is based on a 2-year time lag, and a depreciation rate of $10 \%$. Since these are uncertain parameters, it is useful to test how sensitive these results are to the inclusion of varying assumptions. Such a sensitivity analysis is provided in Table 7 in the "Appendix", and it shows that the results are overall robust with respect to different time lags (3 years) and discount rates (5 and 15\%, respectively). The coefficients associated with the knowledge stock are positive and statistically significant in all the alternative models except one, and there are only minor changes in the remaining coefficient estimates. However, more in-depth research on these assumptions is needed, in part building on the empirical work by Popp (2015).
} 
Table 3 Estimated elasticities of solar PV patent counts with respect to public policy support

\begin{tabular}{|c|c|c|c|c|}
\hline & $\mathrm{S} 1$ & $\mathrm{~S} 2$ & S3 & $\mathrm{S} 4$ \\
\hline \multicolumn{5}{|c|}{ Control variables } \\
\hline OILPRICE & $0.53 * * *$ & $0.62 * * *$ & $0.62 * * *$ & $0.71 * * *$ \\
\hline TRIPS & $1.05 * * *$ & $0.89 * * *$ & $1.09 * * *$ & $0.96 * * *$ \\
\hline \multicolumn{5}{|c|}{ Public policies } \\
\hline$F I T$ & $0.20 * * *$ & $0.16^{* * * *}$ & $0.15^{* * *}$ & $0.11 * *$ \\
\hline$R E C$ & $0.03 * *$ & $0.03 * * *$ & $0.03 * *$ & $0.03 * *$ \\
\hline$R D E X P$ & $0.39 * * *$ & - & $0.24 * * *$ & - \\
\hline RDSTOCK & - & $0.48 * * *$ & - & $0.36 * * *$ \\
\hline \multicolumn{5}{|c|}{ Policy interaction } \\
\hline EXPFIT & - & - & $0.10 * * *$ & $0.10 * *$ \\
\hline EXPREC & - & - & 0.01 & 0.00 \\
\hline
\end{tabular}

$p$ values based on bootstrapped standard errors stratified by country; $* p<0.10 ; * * p<0.05 ; * * * p<0.01$

any of the two public R\&D variables implies (ceteris paribus) a greater spur to patenting activity if an FIT scheme for solar PV is present, compared to a situation where no such scheme is in place. The results from the S3 model specification suggest that a $10 \%$ increase in (lagged) public R\&D expenditures will induce a $2.3 \%$ increase in solar PV patenting activity in the absence of an FIT scheme, but $3.2 \%$ $(2.3+0.9)$ if such a scheme is in use. No corresponding interaction effect between public R\&D and REC schemes can here be found as the associated elasticities are not statistically significant (see Table 3 ). This result thus reinforces the conclusion that the FIT schemes tend to be more innovation-promoting than the REC schemes.

\subsection{Robustness tests on time effects}

Although our four main model specifications include time-specific (global) crude oil prices, we have also estimated alternative models: (a) replacing the oil price variable with time-period effects; (b) including the time-period effects along with the oil price. The results from these new model estimations are reported in Tables 8 and 9, respectively. In the first case (Table 8), the results are overall robust, e.g., also here, we find the evidence of statistically significant policy impacts including the interaction between FIT and public R\&D. There is, in fact, some evidence of a statistically significant interaction also between REC and public R\&D (at least at the $10 \%$ significance level), something which was not found in the main estimations. In the second case (Table 9), we find that the statistically significant interaction between R\&D and FIT remains, but the impact of REC on solar PV patent counts in the absence of any public $R \& D$ support is no longer statistically significant, and this result is in part valid also for FIT. The impacts of public R\&D, no matter how we operationalize this policy, however, remain positive and statistically significant also in the case where no demand-pull policy is in place.

Finally, we also include year-specific dummy variables, in this case, excluding both the crude oil price and the time-period dummies. These model specifications 
thus explicitly incorporate unobserved common shocks beyond the global crude oil price. The results are reported in Table 4. Interestingly, these results illustrate that both of the demand-pull policies have no statistically significant impacts on patent counts unless these are accompanied by public R\&D support to solar PV. The results with respect to the isolated effect of public R\&D support on patent activity are ambiguous, e.g., showing no statistically significant impact when the interaction variable is included. Still, the policy interaction effect between public R\&D support and FIT remains statistically significant also when including the time-specific effects. In fact, in one of the cases, a corresponding interaction effect exists also in the case of public R\&D and REC.

Thus, overall the above robustness tests show that we can reject the null hypothesis that there is no interaction effect between increases in public R\&D in the presence of an FIT scheme on solar PV patent counts. Our key finding of a R\&D-FIT policy interaction effect is, therefore, robust, and there is even some mixed evidence of a similar interaction between REC and public R\&D. However, the results are not entirely robust when it comes to the impacts of both FIT and REC on solar PV patent counts in the absence of a complementing technology-push policy, and similarly for the impact of public R\&D support when there is no demand-pull policy in place. In the latter cases, the results often shows statistically significant impacts but not for all model specifications.

Table 4 Results from the negative binomial models with country- and time-specific effects

\begin{tabular}{lll}
\hline & $\begin{array}{l}\text { Time-specific } \\
\text { effects and } \\
R D E X P\end{array}$ & $\begin{array}{l}\text { Time-specific } \\
\text { effects and } \\
\text { RDSTOCK }\end{array}$ \\
\hline Control variables & & \\
OILPRICE & - & - \\
TRIPS & $6.150^{* * *}(0.000)$ & $6.450^{* * *}(0.000)$ \\
Public policies & & \\
FIT & $0.002(0.460)$ & $0.003(0.238)$ \\
$R E C$ & $0.010(0.676)$ & $0.011(0.617)$ \\
$R D E X P$ & $0.003(0.182)$ & - \\
RDSTOCK & - & $0.000(0.624)$ \\
Policy interaction & & \\
EXPFIT & $0.007 * *(0.050)$ & $0.009 * * *(0.006)$ \\
EXPREC & $0.002(0.231)$ & $0.004 * *(0.021)$ \\
Log-likelihood (NB) & -529.393 & -530.170 \\
Log-likelihood (Poisson) & -885.374 & -885.374 \\
$\alpha$ (overdispersion parameter) & 0.049 & 0.051 \\
& s.e. 0.017 & s.e. 0.018 \\
$x^{2}$ & 711.961 & 710.408 \\
$p>x^{2}$ & 0.000 & 0.000 \\
$N$ & 350 & 350 \\
\hline & & \\
\hline
\end{tabular}

$p$ values in parentheses (based on bootstrapped standard errors stratified by country); * $p<0.10$; ** $p<0.05$; *** $p<0.01$. Stata and the xtnbrg command to account for fixed effects automatically provide the log-likelihood of fitting a Poisson model. This statistic is necessary when conducting a likelihood-ratio overdispersion test 


\section{Discussion}

In this section, we discuss some of the empirical results, i.e., comparing them to the findings of other studies and pointing at some important policy implications. Our results indicate a positive correlation between the FIT levels and solar patenting activity, and this is consistent with the findings of Johnstone et al. (2010). Nevertheless, while we report a statistically significant but lower impact of REC schemes, Johnstone et al. (2010) cannot reject the null hypothesis that this impact is non-existent. They argue that REC schemes are not likely to stimulate innovations in renewable energy technologies that are relatively immature. One plausible explanation for this difference in results is that, in the present work, we focus explicitly on solar PV technology, while Johnstone et al. (2010) adopted a broader definition of solar energy technology that embraces also solar thermal innovations (i.e., innovations in residential systems applied for heating and cooling). Since the REC schemes target technologies used for electricity generation purposes such as solar PV, other types of solar energy technology will not be directly affected by this policy. ${ }^{25}$ Moreover, in the present paper, we also employ a somewhat more updated data set, and also control for the quality of patent applications by focusing on PCT data only.

The heterogeneous impacts of the two types of production support schemes deserve a more in-depth discussion. Both the FIT and the REC schemes can a priori be assumed to have positive innovation impacts. The more profound FIT impacts may in part result from the fact that even though both schemes do not induce strong competition across technologies, in this particular scheme, technical progress increases the producers' surplus and in this way induces them to innovate. Within an REC scheme, the surplus attributed to the producers may be more limited, since the marginal price could decrease as a result of technological advances (Menanteau et al. 2003).

Even more importantly, the two schemes tend to build on different conceptions of what nurtures technological learning and innovation. Innovation can be nurtured by deliberatively making innovation efforts more vulnerable to intense competition from other technologies, but there is also a case for targeted support of protected technological 'niches'. ${ }^{26}$ Our empirical results thus suggest that the protecting strategy provided by the technology-specific FIT schemes has been more successful in inducing solar PV patents than the typically technology-neutral REC policies relying more heavily on 'selection pressure'. In REC schemes, producers will choose to devote most attention to the currently most cost-effective renewable energy technology alternatives accepted under the policy in the short run (Jaffe et al. 2002; Johnstone et al. 2010; Popp 2003). In other words, technology-neutral schemes drive down the learning curve only of the currently most competitive technologies (Schmidt et al. 2016). During the studied period, solar PV was not one of those technologies (IEA 2004). This implies that the REC schemes only stimulated limited solar PV innovation activities. Instead, the technology-specific FIT schemes did

\footnotetext{
25 Braun et al. (2011) also point to the problem of mixing different types of solar technologies when investigating innovation patterns and policy impacts.

26 The economics literature has suggested that a proper balance between competition and monopoly (e.g., oligopoly markets) provides the most fertile ground for innovation (e.g., Baumol 2002).
} 
induce more such activities, and potentially contributed to preventing the lock-out of this technology. In the end, though, the relevant question for policy makers is not really whether to implement technology-neutral or technology-specific policies, but rather to decide on how technology-specific a policy should be both in terms of technologies per se but also in terms of their application (Schmidt et al. 2016).

It should be recognized that there is always the risk that technologies become over-supported through the use of deployment policies, which, in turn, can create a disincentive to innovate in the less mature technologies or applications. In the empirical context of solar PV, Hoppman et al. (2014) emphasize that, for firms pursuing relatively mature PV technologies, deployment policies may reduce the need to invest in longer term explorative activities. On the other hand, the firms that are more focused on the less mature PV solutions may often not be in a position to go beyond exploration through, say, the emergence of specialized manufacturing equipment. For this reason, Hoppman et al. (2014) argue that, although deployment policies are effective in inducing innovation at a general level, such policies "need to be designed with care and should be complemented by supply-side measures to alleviate the risk of technological lock-in," (p. 1001).

Turning to the role of public R\&D in solar PV innovation, our results are in line with those reported by, for instance, Braun et al. (2010) and Johnstone et al. (2010), although these studies neither consider nor test different ways of measuring the role of R\&D support. Our results suggest that public R\&D has been more influential in inducing solar PV patenting activity than policies supporting the diffusion of solar PV (i.e., FIT and REC schemes), thus, suggesting that public support to R\&D generate spillovers that can be used by private companies to develop solar PV technology. These results are also consistent with some previous two-factor learning curve studies showing higher R\&D-induced cost reductions for renewable energy technology such as wind power and solar PV, and often a somewhat less prominent role for learning-by-doing following the diffusion of the technology (e.g., Nemet 2006; Söderholm and Klaassen 2007; Pizer and Popp 2008).

The results from our robustness tests controlling for potential time effects tend to support the notion that technology-push policies are more important for solar PV innovation than any of the two demand-pull policies. These additional results even tend to question the presence of positive impacts of either FIT or REC schemes on solar PV patenting unless accompanied by public R\&D support. At the same time, we obtained additional support for the existence of a policy interaction between public R\&D and both these demand-pull policies. This suggests thus that countries that do not complement demand-pull policies with public R\&D efforts (and vice versa) may experience only modest impacts on patenting activity. This finding to some extent corroborates the remark made by Cohen and Levinthal (1990) that R\&D not only generates new knowledge, it may also contribute to actors' absorptive capacity. This capacity refers to the ability to recognize the value of new, external information, assimilate it, and apply it in future development efforts. In the absence of public R\&D generating spillovers, it may, therefore, be difficult to benefit from the learning that is the outcome of technology deployment.

For this reason, public R\&D programs should typically not cease entirely as the technology matures. Innovation requires both R\&D and learning-by-doing, and for this reason, 
R\&D programs should typically not be designed in isolation from practical application (e.g., Arrow et al. 2009). The gradual diffusion of a certain technology can reveal areas where additional R\&D would be most productive. Our results support the notion that public R\&D support to solar PV is more effective in the presence of FIT schemes, and this provides quantitative support for the argument made by del Río and Bleda (2012) that complementing FITs with public R\&D support will promote innovation. As was noted above, we also find some mixed evidence of a similar interaction effect with REC schemes. ${ }^{27}$ Our results manifest themselves in one of the practical lessons of the failed so-called 'Million Solar Roofs' (1997-2005) program in USA. This program was criticized for lacking the necessary alignment with $R \& D$ efforts, and for not permitting R\&D to influence the program plans and methods (Strahs and Tombari 2006). A follow-up demonstration program, the so-called Solar America Initiative, was, therefore, instead, designed to evade this mistake by mixing technology and market development, with the latter being accompanied with substantial R\&D and venture capital (Hendry et al. 2010). Finally, Watanabe et al. (2000) reports some empirical evidence of how production of solar PV plants created a feedback loop to further R\&D investment in Japan during the 1990s.

In the light of our result on policy interaction, it is worth noting that following the oil crises in the 1970s most developed countries introduced substantial public R\&D support for various renewable energy technologies (including solar PV). Still, during the 1980s, this support was typically not accompanied by explicit demand-pull policies. Our empirical results suggest that this implied lower solar PV innovation activity during this decade, i.e., relative to the level of innovation that could have been achieved had the policies been in force simultaneously.

\section{Concluding remarks and avenues for future research}

This paper investigated the effect on solar photovoltaic (PV) innovation of renewable energy policies and their interaction. Our results indicate that: (a) both feed-in tariff (FIT) schemes and renewable energy certificate (REC) schemes induce solar PV patenting activity, even though the impact of the former policy is found to be more profound; (b) public R\&D support has been more influential than FIT and REC schemes in encouraging solar PV innovation; (c) policy interaction exists in that the innovation effect of public R\&D support is greater at the margin if it is accompanied by the use of (in particular) FIT schemes for solar PV. The results from our robustness tests support the presence of interaction between public R\&D and FIT schemes, while, however, in some parts questioning the evidence of positive impacts of demand-pull policies on solar PV patent counts in the absence of public R\&D support.

Overall, the above results confirm the notion that innovation in the renewable energy field is endogenously determined, and induced by more or less targeted policy instruments. The often-important role of FIT schemes implies in turn that

\footnotetext{
27 A plausible explanation for the less robust results in the REC case is that within these types of schemes, more mature technologies tend to be prioritized, and the policy provides only limited opportunities for continuous technology learning in solar PV, in turn, augmenting the impact of R\&D. The limited innovation impacts of REC schemes have been argued by Bergek and Jacobssson (2010) in their assessment of the Swedish REC policy.
} 
technical innovation (at least in the case of less mature energy technologies) could, in part, be nurtured through some amount of policy protection. The interaction between public R\&D support and the demand-pull policies does not emerge to the same extent in the case of public R\&D and REC schemes. This may be due to the relatively strong technology selection pressure under REC schemes, thus mainly favoring currently cost-effective renewable energy technologies. Still, it should be clear that a number of issues deserve increased attention in future research.

First, the presence of international knowledge and policy spillovers has likely begun to play an increasingly important role in fostering domestic solar PV innovation, not least during the last decade. This requires different sets of model specifications (e.g., Verdolini and Galeotti 2011; Peters et al. 2012), taking into account how national technology-push and demand-pull policies could have both domestic and international impacts. Our results indicate, though, that also this research stream should recognize the presence of important policy interaction effects, such as testing the hypothesis that countries with higher domestic R\&D support will find it easier to benefit from both domestic and foreign demand-pull policies.

Second, while this paper identified an important impact of public R\&D efforts on solar PV innovation, this effect may be less pronounced in the case of more mature technologies as well as over time as less-developed technologies mature. This needs to build on complementing research on the time lags between public R\&D support and private patents; as shown by Popp (2015), these may be long and differ across technologies. A comprehensive understanding of such differential impacts is important information for policy-making. Such research must also increasingly attempt to distinguish between different designs of public policies. For instance, Liang and Fiorino (2013) argue that, for renewable energy innovation, the level of R\&D support loses explanatory power to policy stability in the long run, thus, suggesting that the ways in which policies are implemented (e.g., perceived stability over time) may matter just as much as the level of support provided. Peters et al. (2012) also emphasize the need for better addressing the effects of design features of specific policies, not least the used of time-declining rate in many countries.

Third, the interaction between private and public R\&D during the innovation process also deserves more in-depth empirical research. Fujii and Managi (2016) provide an analysis of the role of the private and public sectors in influencing environmental technology inventions. The roles of private and public R\&D, respectively, likely differ as different technologies develop. ${ }^{28}$ Private R\&D efforts may become more pronounced as a technology matures, while public R\&D policy often tends to encourage more risk-taking and exploratory $R \& D$ activities characterized by greater uncertainty in the distribution of project payoffs (Ek and Söderholm 2010). The role of public policy as such may change (and, perhaps, should change) as the technology develops from basic R\&D to diffusion growth in the market. Our results confirm the importance of acknowledging the interaction and the iterations between

\footnotetext{
${ }^{28}$ Research that is able to distinguish more clearly between the impacts of private versus public R\&D as well as public and private patents could also avoid the potential problem of endogeneity of the policy variables.
} 
R\&D and diffusion policy (e.g., FIT schemes), but this also calls for more detailed studies employing more disaggregated data on policies, technology, and actors. For instance, the case of solar PV also illustrates the importance of recognizing the distinction between process and product innovation, not least contributing to widely differing technology life cycles for various technologies (see Huenteler et al. 2016). In addition, in this context, there should also be scope for novel methodological approaches to studying the relationship between efficiency, innovation, and environmental policy design (see, for instance, Johnstone et al. 2017).

Fourth, and finally, it needs to be emphasized that the type of empirical research presented in this paper should also be complemented with normative research on the economic efficiency of different innovation policies and policy mixes in the renewable energy sector (e.g., Aalbers et al. 2013).

Acknowledgements Financial support from the Swedish Research Council Formas and the Ragnar Söderberg Research Foundation is gratefully acknowledged, as are valuable comments from Göran Bostedt, Carol Dahl, Carolyn Fischer, Nicholas Hanley, Richard S. Tol, and two anonymous reviewers on earlier versions of the manuscript. Any remaining errors, though, reside solely with the authors.

Open Access This article is distributed under the terms of the Creative Commons Attribution 4.0 International License (http://creativecommons.org/licenses/by/4.0/), which permits unrestricted use, distribution, and reproduction in any medium, provided you give appropriate credit to the original author(s) and the source, provide a link to the Creative Commons license, and indicate if changes were made.

\section{Appendix}

See Tables 5, 6, 7, 8, and 9.

Table 5 Correlation coefficients for independent variables

\begin{tabular}{lcrrrrrrr}
\hline & \multicolumn{1}{c}{ FIT } & \multicolumn{1}{c}{ REC } & RDEXP & RDSTOCK & TRIPS & OILPRICE & EXPFIT & EXPREC \\
\hline FIT & 1.000 & & & & & & & \\
REC & -0.0087 & 1.000 & & & & & & \\
RDEXP & 0.007 & -0.045 & 1.000 & & & & & \\
RDSTOCK & 0.126 & -0.050 & 0.905 & 1.000 & & & & \\
TRIPS & 0.471 & 0.205 & 0.120 & 0.234 & 1.000 & & & \\
OILPRICE & 0.062 & 0.127 & -0.032 & -0.111 & -0.191 & 1.000 & & \\
EXPFIT & 0.479 & -0.065 & 0.277 & 0.408 & 0.220 & -0.092 & 1.000 & \\
EXPREC & -0.067 & 0.065 & 0.611 & 0.575 & 0.160 & 0.110 & -0.050 & 1.000 \\
\hline
\end{tabular}


Table 6 Estimation results from the negative binomial models with country-specific effects and using robust standard errors clustered at the country level

\begin{tabular}{|c|c|c|c|c|}
\hline & S1 & S2 & S3 & S4 \\
\hline \multicolumn{5}{|l|}{ Control variables } \\
\hline OILPRICE & $0.012 * * *(0.009)$ & $0.014 * * *(0.000)$ & $0.014 * * *(0.000)$ & $0.016^{* * *}(0.000)$ \\
\hline TRIPS & $2.318 * * *(0.000)$ & $1.970 * * *(0.000)$ & $2.405 * * *(0.000)$ & $2.118 * * *(0.000)$ \\
\hline \multicolumn{5}{|l|}{ Public policies } \\
\hline FIT & $0.023^{* * *}(0.000)$ & $0.019^{* * *}(0.000)$ & $0.017 * * *(0.005)$ & $0.013 * *(0.010)$ \\
\hline$R E C$ & $0.093 * *(0.010)$ & $0.103 * * *(0.036)$ & $0.085^{* *}(0.031)$ & $0.093 * *(0.046)$ \\
\hline RDEXP & $0.021^{* * *}(0.000)$ & - & $0.013^{* * *}(0.000)$ & - \\
\hline RDSTOCK & - & $0.004 * * *(0.000)$ & - & $0.003 * * *(0.000)$ \\
\hline \multicolumn{5}{|l|}{ Policy interaction } \\
\hline EXPFIT & - & - & $0.019^{* * *}(0.000)$ & $0.019^{* * *}(0.000)$ \\
\hline EXPREC & - & - & $0.004(0.059)$ & $0.000(0.410)$ \\
\hline Log-likelihood (NB) & -628.104 & -623.606 & -619.973 & -615.436 \\
\hline Log-likelihood (Poisson) & -825.172 & -806.821 & -812.110 & -796.330 \\
\hline \multirow{2}{*}{$\begin{array}{l}\alpha \text { (overdispersion param- } \\
\text { eter) }\end{array}$} & 0.403 & 0.356 & 0.349 & 0.317 \\
\hline & s.e. 0.096 & s.e. 0.087 & s.e. 0.061 & s.e. 0.056 \\
\hline$N$ & 350 & 352 & 350 & 350 \\
\hline
\end{tabular}

$p$ values in parentheses (based on robust standard errors clustered at the country level); $* p<0.10$; $* * p<0.05 ; * * * p<0.01$. Stata automatically provides the log-likelihood of fitting a Poisson model. This statistic is necessary when conducting a likelihood-ratio overdispersion test 


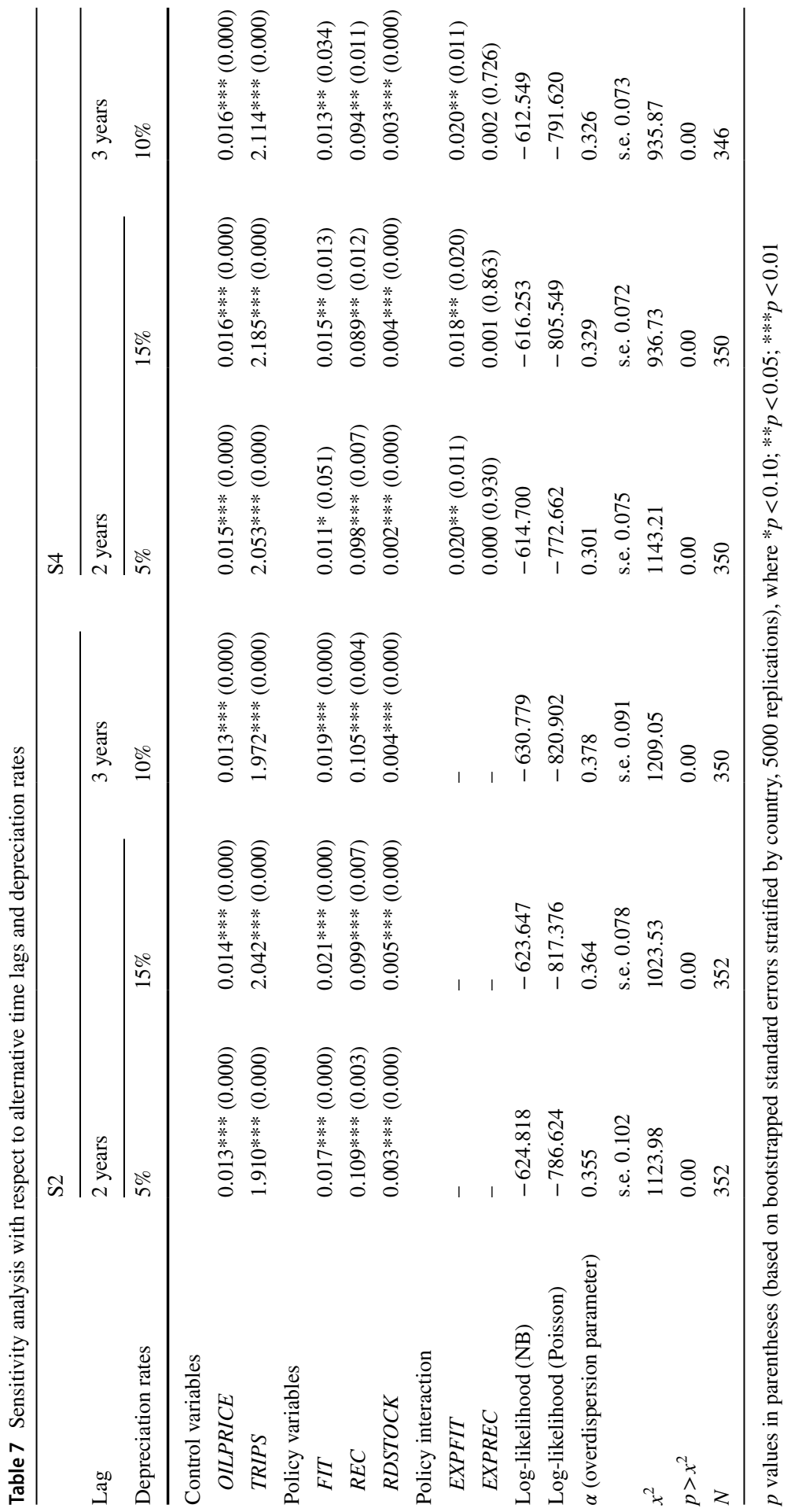


Table 8 Estimation results with time-period dummy variables

\begin{tabular}{|c|c|c|c|c|}
\hline & S1 & $\mathrm{S} 2$ & S3 & S4 \\
\hline \multicolumn{5}{|l|}{ Control variables } \\
\hline$D_{1986-1995}$ & $1.376^{* * *}(0.000)$ & $1.047 * * *(0.000)$ & $1.301 * * *(0.000)$ & $1.204 * * *(0.000)$ \\
\hline$D_{1996-2008}$ & $3.326^{* * * *}(0.000)$ & $2.806 * * *(0.000)$ & $3.278 * * *(0.000)$ & $3.131 * * *(0.000)$ \\
\hline \multicolumn{5}{|l|}{ Public policies } \\
\hline$F I T$ & $0.027 * * *(0.000)$ & $0.024 * * *(0.000)$ & $0.022 * * *(0.000)$ & $0.020 * * *(0.000)$ \\
\hline$R E C$ & $0.126^{* * *}(0.000)$ & $0.138 * * *(0.000)$ & $0.123 * * *(0.000)$ & $0.127 * * *(0.000)$ \\
\hline$R D E X P$ & $0.019 * * *(0.000)$ & - & $0.009 * *(0.038)$ & - \\
\hline RDSTOCK & - & $0.003 * * *(0.000)$ & - & $0.001(0.260)$ \\
\hline \multicolumn{5}{|l|}{ Policy interaction } \\
\hline EXPFIT & - & - & $0.014 * * *(0.008)$ & $0.017 * * *(0.005)$ \\
\hline EXPREC & - & - & $0.007 *(0.096)$ & $0.008 *(0.054)$ \\
\hline Log-likelihood (NB) & -619.899 & -623.016 & -614.007 & -615.402 \\
\hline Log-likelihood (Poisson) & -1033.848 & -1001.149 & -980.556 & -958.944 \\
\hline \multirow[t]{2}{*}{$\alpha$ (overdispersion parameter) } & 0.438 & 0.449 & 0.413 & 0.423 \\
\hline & s.e. 0.075 & s.e. 0.077 & s.e. 0.076 & s.e. 0.076 \\
\hline$x^{2}$ & 885.67 & 1093.84 & 791.96 & 852.68 \\
\hline$p>x^{2}$ & 0.000 & 0.000 & 0.000 & 0.000 \\
\hline$N$ & 350 & 352 & 350 & 350 \\
\hline
\end{tabular}

$p$ values in parentheses (based on bootstrapped standard errors stratified by country, 5000 replications), where $* p<0.10 ; * * p<0.05 ; * * * p<0.01$

Table 9 Estimation results with oil price and time-period dummy variables

\begin{tabular}{|c|c|c|c|c|}
\hline & $\mathrm{S} 1$ & $\mathrm{~S} 2$ & S3 & $\mathrm{S} 4$ \\
\hline \multicolumn{5}{|l|}{ Control variables } \\
\hline$D_{1986-1995}$ & $2.576 * * *(0.000)$ & $2.324 * * *(0.000)$ & $2.465 * * *(0.000)$ & $2.352 * * *(0.000)$ \\
\hline$D_{1996-2008}$ & $4.390 * * *(0.000)$ & $3.966^{* * *}(0.000)$ & $4.361 * * *(0.000)$ & $4.173 * * *(0.000)$ \\
\hline OILPRICE & $0.024 * * *(0.000)$ & $0.025^{* * *}(0.000)$ & $0.025 * * *(0.000)$ & $0.025^{* * *}(0.000)$ \\
\hline \multicolumn{5}{|l|}{ Public policies } \\
\hline$F I T$ & $0.012 * * *(0.002)$ & $0.010 * * *(0.010)$ & $0.007 *(0.067)$ & $0.006(0.130)$ \\
\hline$R E C$ & $0.037(0.190)$ & $0.045(0.118)$ & $0.034(0.226)$ & $0.037(0.188)$ \\
\hline$R D E X P$ & $0.013 * * *(0.000)$ & - & $0.009 * *(0.038)$ & - \\
\hline RDSTOCK & - & $0.003 * * *(0.000)$ & - & $0.001 *(0.081)$ \\
\hline \multicolumn{5}{|l|}{ Policy interaction } \\
\hline EXPFIT & - & - & $0.017 * * *(0.000)$ & $0.018 * * *(0.005)$ \\
\hline EXPREC & - & - & $0.004 *(0.067)$ & $0.003(0.140)$ \\
\hline Log-likelihood (NB) & -587.486 & -590.114 & -578.827 & -579.582 \\
\hline Log-likelihood (Poisson) & -712.574 & -712.987 & -691.352 & -690.769 \\
\hline \multirow[t]{2}{*}{$\alpha$ (overdispersion parameter) } & 0.206 & 0.203 & 0.182 & 0.182 \\
\hline & s.e. 0.042 & s.e. 0.042 & s.e. 0.038 & s.e. 0.038 \\
\hline$x^{2}$ & 595.78 & 593.43 & 613.09 & 611.58 \\
\hline$p>x^{2}$ & 0.000 & 0.000 & 0.000 & 0.000 \\
\hline$N$ & 350 & 352 & 350 & 350 \\
\hline
\end{tabular}

$p$ values in parentheses (based on bootstrapped standard errors stratified by country, 5000 replications), where $* p<0.10$; ** $p<0.05$; *** $p<0.01$ 


\section{References}

Aalbers R, Shestalova V, Kocsis V (2013) Innovation policy for directed technical change in the power sector. Energy Policy 63:1240-1250

Acemoglu D, Aghion P, Bursztyn L, Hemous D (2012) The environment and directed technical change. Am Econ Rev 102:131-166

Allison P, Waterman R (2002) Fixed-effects negative binomial regression models. Sociol Methodol 32:247-265

Arrow KJ, Cohen L, David PA, Hahn RW, Kolstad CD, Lane L, Montgomery WD, Nelson RR, Noll RG, Smith AE (2009) A statement on the appropriate role for research and development in climate Policy. Economists' voice, vol 6. http://www.bepress.com. Accessed 10 Dec 2009

Arthur WB (1989) Competing technologies, increasing returns, and lock-in by historical events. Econ J 99:116-131

Azar C, Sandén BA (2011) The elusive quest for technology-neutral policies. Environ Innov Soc Transit 1:135-139

Baumol WJ (2002) The free-market innovation machine. Princeton University Press, Princeton

Beise-Zee R, Rammer C (2006) Local user-producer interaction in innovation and export performance of firms. Small Bus Econ 27:207-222

Bergek A, Berggren C (2014) The impact of environmental policy instruments on innovation: a review of energy and automotive industry studies. Ecol Econ 106:112-123

Bergek A, Jacobssson S (2010) Are tradable green certificates a cost-efficient policy driving technical change or a rent-generating machine? Lessons from Sweden 2003-2008. Energy Policy 38:1255-1271

Bradford T (2006) Solar revolution: the economic transformation of the global energy industry. MIT Press, Cambridge

Braun F, Schmidt-Ehmcke J, Zloczysti P (2010) Innovative activity in wind and solar technology: empirical evidence on knowledge spillovers using patent data. DIW Berlin Discussion Papers 993, Deutsches Institut für Wirtschaftsforschung, Berlin

Braun F, Hooper E, Wand R, Zloczysti P (2011) Holding a candle to innovation in concentrating solar power technologies: a study drawing on patent data. Energy Policy 39:2441-2456

Brunnermeier S, Cohen A (2003) Determinants of environmental innovation in US manufacturing industries. J Environ Econ Manag 45:278-293

Cameron A, Trivedi P (1998) Regression analysis of count data. Cambridge University Press, New York

Campoccia A, Dusonchet L, Telaretti E, Zizzo G (2009) Comparative analysis of different supporting measures for the production of electrical energy by solar PV and wind systems: four representative European cases. Sol Energy 83:287-297

Carrión-Flores C, Innes R (2010) Environmental innovation and environmental performance. J Environ Econ Manag 59:27-42

Cerveny M, Resch G (1998) Feed-in tariffs and regulations concerning renewable energy electricity generation in European countries. Energieverwertungsagentur (E.V.A.), Vienna

Cohen WM, Levinthal DA (1990) Absorptive capacity: a new perspective on learning and innovation. Admin Sci Q 35:128-152

Comins JA, Leyersdorff L (2018) Determining the foundational patents of photovoltaic materials: an application of patent citation spectroscopy. J Sci Res 7:79-83

Costantini V, Crespi F, Martini C, Pennacchio L (2015) Demand-pull and technology-push public support for eco-innovation: the case of the biofuels sector. Res Policy 44:577-595

Costantini V, Crespi F, Palma A (2017) Characterizing the policy mix and its impact on eco-innovation: a patent analysis of energy-efficient technologies. Res Policy 46:799-819

Couture T, Gagnon Y (2010) An analysis of feed-in tariff remuneration models: implications for renewable energy investment. Energy Policy 38:955-965

De la Tour A, Glachant M, Ménière Y (2011) Innovation and international technology transfer: the case of the chinese photovoltaic industry. Energy Policy 39(2):761-770

De la Tour A, Glachant M, Joëts M (2013) How do solar photovoltaic feed-in tariffs interact with solar panel and silicon prices? An empirical study, Working Paper 13-ME-04. CERNA, MINES ParisTech, Paris

Dechezleprêtre A, Glachant M, Haščič I, Johnstone N, Méniére Y (2011) Invention and transfer of climate change-mitigation technologies: a global analysis. Rev Environ Econ Policy 5:109-130 
Del Río P, Bleda M (2012) Comparing the innovation effects of support schemes for renewable electricity technologies: a function of innovation approach. Energy Policy 50:272-282

Downing P, White L (1986) Innovation in pollution control. J Environ Econ Manag 13:18-29

Dusonchet L, Telaretti E (2010) Economic analysis of different supporting policies for the production of electrical energy by solar photovoltaics in Western European Union countries. Energy Policy 38:3297-3308

Ek K, Söderholm P (2010) Technology learning in the presence of public R\&D: the case of european wind power. Ecol Econ 69:2356-2362

Emodi NV, Shagdarsuren G, Tiky AY (2015) Influencing factors promoting technological innovation in renewable energy. Int J Energy Econ Policy 5:889-900

Fischer C, Newell R (2008) Environmental and technology policies for climate mitigation. J Environ Econ Manag 55:142-162

Foray D (ed) (2009) The new economics of technology policy. Edward Elgar, Cheltenham

Fouquet D, Johansson T (2008) European renewable energy policy at crossroads: focus on electricity support mechanisms. Energy Policy 36:4079-4092

Foxon TJ, Gross R, Chase A, Howes J, Arnall A, Anderson D (2005) UK innovation systems for new and renewable energy technologies: drivers, barriers and systems failures. Energy Policy 33:2123-2137

Frietsch R, Schmoch U (2010) Transational patents and international markets. Scientometrics 82:185-200

Fujii H, Managi S (2016) Research and development strategy for environmental technology in Japan: a comparative study of the private and public sectors. Technol Forecast Soc Chang 112:293-302

Gillingham K, Newell RG, Pizer WA (2008) Modeling endogenous technological change for climate policy analysis. Energy Econ 30:2734-2753

Gipe P (2013) Tables of feed-in tariffs worldwide. http://www.wind-works.org/cms/index.php?id=92. Accessed 5 Apr 2013

Gould W, Pitblado J, Sribney W (2006) Maximum likelihood estimation with stata, 3rd edn. Stata Press, College Station

Greene W (2004) The behaviour of the maximum likelihood estimator of limited dependent variable models in the presence of fixed effects. Econ J 7:98-119

Griliches Z (1995) R\&D and productivity: econometric results and measurement issues. In: Stoneman P (ed) Handbook of economics on innovation and technological change. Blackwell, Oxford

Guimarães P (2008) The fixed effects negative binomial model revisited. Econ Lett 99:63-66

Hausman J, Hall B, Griliches Z (1984) Economic models for count data with an application to the patents-R\&D relationship. Econometrica 52:909-938

Hendry C, Harborne P, Brown J (2010) So what do innovating companies really get from publicly funded demonstration project and trials? Innovation lessons from solar photovoltaics and wind. Energy Policy 38:4507-4519

Hicks J (1932) The theory of wages. Macmillan, London

Hilbe J (2011) Negative binomial regression. Cambridge University Press, New York

Hommels A, Peters P, Bijker W (2007) Techno therapy or nurtured niches? Technology studies and the evaluation of radical innovations. Res Policy 36:1088-1099

Hoppman J, Huenteler J, Girod B (2014) Compulsive policy-making-the evolution of the German feedin tariff system for solar photovoltaic power. Res Policy 43:1422-1441

Hoppmann J, Peters M, Schneider M, Hoffman VH (2013) The two faces of market support-how deployment policies affect technological exploration in the solar photovoltaic industry. Res Policy 42:989-1003

Huenteler J, Schmidt TS, Ossenbrink J, Hoffman VH (2016) Technology life-cycles in the energy sector-technological characteristics and the role of deployment for innovation. Technol Forecast Soc Chang 104:102-121

International Energy Agency (IEA) (2004) Renewable energy-market and policy trends in IEA countries. OECD, Paris

International Energy Agency (IEA) (2010) Technology roadmap-solar photovoltaic energy. OECD, Paris

International Energy Agency (IEA) (2012a) Global renewable energy policies and measures database. OECD, Paris

International Energy Agency (IEA) (2012b) Policies and measures database. OECD, Paris

International Energy Agency (IEA) (2013) Energy technology R\&D statistics database. OECD, Paris International Energy Agency (IEA) (2014a) Technology roadmap—solar photovoltaic energy. OECD, Paris 
International Energy Agency (IEA) (2014b) Trends 2014 in photovoltaic applications: survey report of selected IEA countries between 1992 and 2013. OECD, Paris

International Energy Agency (IEA) (2015) Energy prices and taxes statistics. OECD, Paris

Jaffe A (1988) Demand and supply influences in R\&D intensity and productivity growth. Rev Econ Stat 70:431-437

Jaffe A, Newell R, Stavins R (2002) Environmental policy and technological change. Environ Resour Econ 22:41-69

Jaumotte F, Pain N (2005) From ideas to development: the determinants of R\&D and patenting, Working Paper No. 457. OECD, Paris

Johnson E (2014) The cost of carbon dioxide abatement from state renewable portfolio standards. Resour Energy Econ 36:332-350

Johnstone N, Haščič I, Popp D (2010) Renewable energy policies and technological innovation: evidence based on patent counts. Environ Resour Econ 45:133-155

Johnstone N, Managi S, Cárdenas Rodriguez M, Haščič I, Fujii H, Souchler M (2017) Environmental policy design, innovation and efficiency gains in electricity generation. Energy Econ 63:106-115

Karmarkar-Deshmukh R, Pray C (2009) Private sector innovation in biofuels in the United States: induced by prices or policies? AgBioForum 12:141-148

Kirkegaard J, Hanemann T, Weischer L, Miller M (2010) Toward a sunny future? Global integration in the solar PV industry, Working Paper Series 10-6. World Resources Institute and Peterson Institute for International Economics, Washington DC

Klaassen G, Miketa A, Larsen K, Sundqvist T (2005) The impact of R\&D on innovation for wind energy in Denmark, Germany and the United Kingdom. Ecol Econ 54:227-240

Klein A, Held A, Ragwitz M, Resch G, Faber T (2010) Evaluation of different feed-in tariff design options: best practice paper for the international feed-in cooperation, 3rd edn. Energy Economics Group and Fraunhofer Institute for Systems and Innovation Research, Karlsruhe

Langniss O, Diekmann J, Lehr U (2009) Advanced mechanisms for the promotion of renewable energy: models for the future evolution of the German Renewable Energy Act. Energy Policy 37:1289-1297

Lanjouw J, Mody A (1996) Innovation and the international diffusion of environmentally responsive technology. Res Policy 25:549-571

Lanzi E, Sue Wing I (2011) Directed technical change in the energy sector: an empirical test of induced directed innovation. In: Paper presented at the WCERE 2010 conference, Montreal, 28 June-2 July

Lee K, Lee S (2013) Patterns of technological innovation and evolution in the energy sector: a patentbased approach. Energy Policy 59:415-432

Lehmann P, Söderholm P (2018) Can technology-specific deployment policies be cost-effective? The case of renewable energy support schemes. Environ Resour Econ 71:475-505

Liang J, Fiorino D (2013) The implications of policy stability for renewable energy innovation in the United States, 1974-2009. Policy Stud J 41:97-118

Lindman Å, Söderholm P (2016) Wind energy and green economy in Europe: measuring policy-induced innovation using patent data. Appl Energy 179:1351-1359

Maddala G (1983) Limited-dependent and qualitative variables in econometrics. Cambridge University Press, Cambridge

McVeigh J, Burtraw D, Darmstadter J, Palmer K (2000) Winner, loser or innocent victim? Has renewable energy performed as expected? Sol Energy 68:237-255

Menanteau P, Finon D, Lamy M-L (2003) Prices versus quantities: choosing policies for promoting the development of renewable energy. Energy Policy 31:799-812

Mendonça M (2007) Feed-in tariffs: accelerating the deployment of renewable energy. EarthScan, London

Nemet GF (2006) Beyond the learning curve: factors influencing cost reductions in photo-voltaics. Energy Policy 34:3218-3232

Nesta L, Vona F, Nicolli F (2014) Environmental policies, competition and innovation in renewable energy. J Environ Econ Manag 67(3):396-411

Newell R, Jaffe A, Stavins R (1999) The induced innovation hypothesis and energy-saving technological change. Q J Econ 114:941-975

Nicolli F, Vona F (2014) Heterogeneous policies, heterogeneous technologies: the case of renewable energy, OFCE Working Paper 2014:15. OFCE Sciences Po, Skema Business School, France

Nicolli F, Johnstone N, Söderholm P (2012) Resolving market failures in recycling markets: the role of technological innovation. Environ Econ Policy Stud 14:261-288 
Noailly J, Batrakova S (2010) Stimulating energy-efficient innovations in the Dutch Building Sector: empirical evidence from patent counts and policy lessons. Energy Policy 38:7803-7817

Noailly J, Smeets R (2012) Directing technical change from fossil-fuel to renewable energy innovation: an empirical application using firm-level patent data. CPB Discussion Paper No. 237. Netherlands Bureau for Economic Policy Analysis, The Hague

Nordhaus WD (2002) Modeling induced innovation in climate-change policy. In: Grubler A, Nakicenovic N, Nordhaus WD (eds) Technological change and the environment. Resources for the Future Press, Washington DC

Organisation for Economic Cooperation and Development (OECD) (2009) OECD Patent Statistics Manual. OECD Publishing, Paris

Organisation for Economic Cooperation and Development (OECD) (2013) Patents by main technology and by international patent classification (IPC). OECD Patent Database, Paris

Peters M, Schneider M, Griesshaber T, Hoffmann V (2012) The impact of technology-push and demandpull policies on technical change-does the locus of policies matter? Res Policy 41:1296-1308

Pizer WA, Popp D (2008) Endogenizing technological change: matching empirical evidence to modeling needs. Energy Econ 30:2754-2770

Popp D (2002) Induced innovation and energy prices. Am Econ Rev 92:160-180

Popp D (2003) Pollution Control Innovations and the Clear Air Act of 1990. J Policy Anal Manag 22:641-660

Popp D (2015) Using scientific publications to evaluate government R\&D spending: the case of energy. CESifo Working Paper No. 5442. Center for Economic Studies and Ifo Institute, Munich

Popp D, Haščič I, Medhi N (2011) Technology and the diffusion of renewable energy. Energy Econ 33:648-662

Reichelstein S, Sahoo A (2018) Relating product prices to long-run marginal cost: evidence from solar photovoltaic modules. Contemp Account Res. https://doi.org/10.1111/1911-3846.12319

Renewable Energy Policy Network for the 21st Century (REN21) (2010) Renewables 2010 Global Status Report. REN21 Secretariat, Paris

Rosenberg N (1982) Inside the black box: technology and economics. Cambridge University Press, Cambridge

Rübbelke D, Weiss P (2011) Environmental regulations, market structure and technological progress in renewable energy technology - a panel data study on wind turbines. FEEM Working Paper No. 581.2011. Fondazione Eni Enrico Mattei, Milan

Sagar AD, Zwaan B (2006) Technological innovation in the energy sector: R\&D, deployment and learning-by-doing. Energy Policy 34:2601-2608

Schankerman M (1998) How valuable is patent protection? Estimates by technology field. RAND J Econ 29:77-107

Schmidt TS, Sewerin S (2018) Measuring the temporal dynamics of policy mixes_an empirical analysis of renewable energy policy mixes' balance and design features in nine countries. Res Policy. https ://doi.org/10.1016/j.respol.2018.03.012

Schmidt TS, Battke B, Grosspietsch D, Hoffman VH (2016) Do deployment policies pick technologies by (not) picking applications? A simulation of investment decisions in technologies with multiple applications. Res Policy 45:1965-1983

Schmoch U (1997) Indicators and the relations between science and technology. Scientometrics 38:103-116

Smith A, Raven R (2012) What is protective space? Reconsidering niches in transitions to sustainability. Res Policy 41:1025-1036

Söderholm P, Klaassen G (2007) Wind power in Europe: a simultaneous innovation-diffusion model. Environ Resour Econ 36:163-190

Strahs G, Tombari C (2006) Laying the foundation for a solar America: the million solar roofs initiative. US Department of Energy, Oak Ridge

Timilsina G, Kurdgelashvili L, Narbel P (2011) A review of solar energy-markets, economics and policies, Policy Research Working Paper Series 5845. The World Bank, Washington DC

Unruh GC (2000) Understanding carbon lock-in. Energy Policy 28:817-830

Verdolini E, Galeotti M (2011) At home and abroad: an empirical analysis of innovation and diffusion in energy technologies. J Environ Econ Manag 61:119-134

Von Hippel E, Tyre MJ (1995) How learning by doing is done: problem identification in novel process equipment. Res Policy 24:1-12 
Walz R, Ragwitz M, Schleich J (2008) Regulation and Innovation: The Case of Renewable Energy Technologies. DIME Working Paper No. 2. Fraunhofer Institute for Systems and Innovation Research, Karlsruhe

Watanabe C, Wakabayashi K, Miyazawa T (2000) Industrial dynamism and the creation of a "virtuous cycle" between R\&D, market growth and price reduction: the case of photovoltaic power generation (PV) development in Japan. Technovation 20:299-312

Wiesenthal, T., G. Leduc, H-G. Schwarz and K. Haegeman (2009). R\&D Investment in the Priority Technologies of the European Strategic Energy Technology Plan. JRC Reference Reports (EUR 23944 EN), Institute for Prospective Technological Studies, Luxembourg 